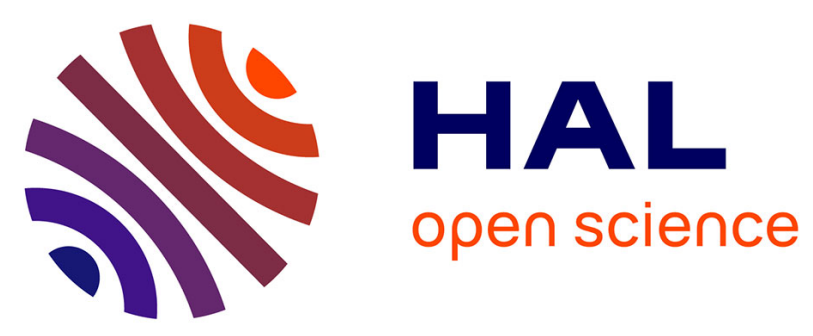

\title{
Coupling fluid flow, heat transfer and thermal denaturation-aggregation of beta-lactoglobulin using an Eulerian/Lagrangian approach
}

Etienne E. Chantoiseau, Artemio Plana-Fattori, C. Doursat, D. Flick

\section{- To cite this version:}

Etienne E. Chantoiseau, Artemio Plana-Fattori, C. Doursat, D. Flick. Coupling fluid flow, heat transfer and thermal denaturation-aggregation of beta-lactoglobulin using an Eulerian/Lagrangian approach. Journal of Food Engineering, 2012, 113 (2), pp.234-244. 10.1016/j.jfoodeng.2012.05.043 . hal-00841043

HAL Id: hal-00841043

https://institut-agro-rennes-angers.hal.science/hal-00841043

Submitted on 16 Dec 2020

HAL is a multi-disciplinary open access archive for the deposit and dissemination of scientific research documents, whether they are published or not. The documents may come from teaching and research institutions in France or abroad, or from public or private research centers.
L'archive ouverte pluridisciplinaire HAL, est destinée au dépôt et à la diffusion de documents scientifiques de niveau recherche, publiés ou non, émanant des établissements d'enseignement et de recherche français ou étrangers, des laboratoires publics ou privés. 


\section{Accepted Manuscript}

Coupling fluid flow, heat transfer and thermal denaturation-aggregation of betalactoglobulin using an Eulerian/Lagrangian approach

Etienne Chantoiseau, Artemio Plana-Fattori, Christophe Dousat, Denis Flick

PII: S0260-8774(12)00275-0

DOI: http://dx.doi.org/10.1016/j.jfoodeng.2012.05.043

Reference: JFOE 6979

To appear in: Journal of Food Engineering

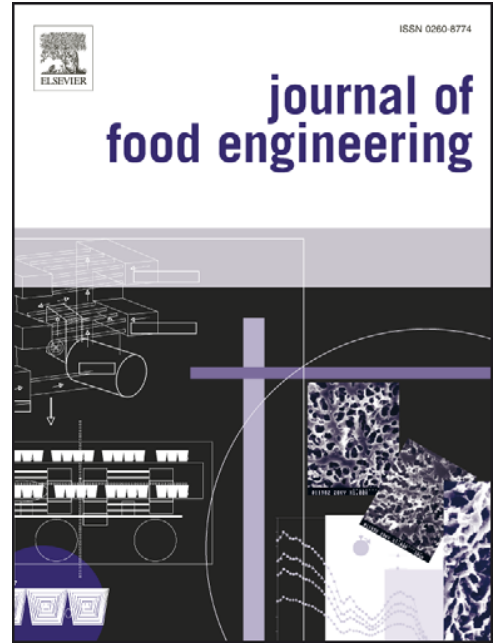

Received Date: $\quad 17$ August 2011

Revised Date: $\quad 3$ May 2012

Accepted Date: $\quad 27$ May 2012

Please cite this article as: Chantoiseau, E., Plana-Fattori, A., Dousat, C., Flick, D., Coupling fluid flow, heat transfer and thermal denaturation-aggregation of beta-lactoglobulin using an Eulerian/Lagrangian approach, Journal of Food Engineering (2012), doi: http://dx.doi.org/10.1016/j.jfoodeng.2012.05.043

This is a PDF file of an unedited manuscript that has been accepted for publication. As a service to our customers we are providing this early version of the manuscript. The manuscript will undergo copyediting, typesetting, and review of the resulting proof before it is published in its final form. Please note that during the production process errors may be discovered which could affect the content, and all legal disclaimers that apply to the journal pertain. 
Title:

Coupling fluid flow, heat transfer and thermal denaturation-aggregation of beta-lactoglobulin using an Eulerian/Lagrangian approach

Authors:

Etienne CHANTOISEAU

Artemio PLANA-FATTORI

Christophe DOUSAT

Denis FLICK

Affiliation (all the authors):

(1) AgroParisTech, UMR1145 Ingénierie Procédés Aliments, Massy, France

(2) INRA, UMR1145 Ingénierie Procédés Aliments, Massy, France

(3) Le Cnam, UMR1145 Ingénierie Procédés Aliments, Massy, France

Corresponding Author Address:

Artemio Plana Fattori

AgroParisTech - MMIP

16 rue Claude Bernard, 75231 Paris CEDEX 5, France

phone: +33.1.44.08.86.84

fax: +33.1.44.08.16.66

e-mail: artemio.planafattori@agroparistech.fr 


\section{Introduction}

Thermal processing techniques have been applied to improve quality and safety of food products and to extend their shelf life (Wang and Sun, 2006). In the dairy industry, billions of liters of milk are processed every year for pasteurization or sterilization. Fouling of heat exchangers is an issue because it reduces heat transfer efficiency and increases pressure drop, hence affecting the economy of processing plants. As a result of fouling, there is the possibility of deterioration in the product quality because the process fluid cannot be heated up to the required temperature. Although representing only about $5 \%$ of the milk solids, whey proteins account for more than $50 \%$ of the fouling deposits occurring at temperatures below $110{ }^{\circ} \mathrm{C}$ (Bansal and Chen, 2006). The understanding of fouling mechanisms has progressed since the 1970's, which include not only the aggregation of beta-lactoglobulin with other protein molecules but also the influence of aggregates on heat transfer between walls and the process fluid.

The structure of whey proteins can be significantly altered depending on the duration and severity of heat treatment. With increasing temperatures whey proteins unfold and can aggregate, either themselves or with other species. Aggregates including whey proteins are relevant to human nutrition (de Wit, 1998) and health (Navarra et al., 2007). Among other applications in the food industry, whey protein aggregates with particle sizes ranging between 0.1 and 20 micrometers have been incorporated as successful fat replacers into low-fat stirred yoghurts, because they provide sensory sensations close to those associated with the presence of fat milk (Janhoj et al., 2006). Modeling of whey protein aggregation induced by heat treatment can therefore provide assistance in understanding biophysical processes as well as in designing processing units. 
This study is devoted to the numerical modeling of the evolution of a suspension of whey proteins under continuous thermal treatment. The beta-lactoglobulin is taken as an example among the whey proteins, and for the sake of simplicity it is taken alone in the suspension. It is the most abundant protein found in the whey fraction of cow milk, and also the dominant whey protein in heat-induced fouling (Bansal and Chen, 2006). Its structure and properties have been studied since the 1930's with the help of different biochemical techniques (Sawyer and Kontopidis, 2000). Denaturation-aggregation of beta-lactoglobulin occurs following different stages: i) the dissociation of native dimers existing under physiological conditions into native monomers, when the temperature increases above $40{ }^{\circ} \mathrm{C}$; ii) the reversible partial unfolding of monomers and the formation of a thermally induced molten globule state when the temperature increases above $60{ }^{\circ} \mathrm{C}$; and iii) depending on operating conditions, the occurrence of irreversible intra-molecular interactions resulting in the formation of aggregates (Tolkach and Kulozik, 2007). An overview about the thermal behavior of the beta-lactoglobulin at temperatures up to $150{ }^{\circ} \mathrm{C}$, including the influence of pH, has been presented by de Wit (2009).

Reaction kinetic approaches have been applied for studying the thermal denaturationaggregation of the beta-lactoglobulin. Such a strategy can provide information related to the main stages of the proteins evolution under heat treatment, namely the concentration of native monomers and that of partially unfolded monomers, and then the aggregates concentration (Tolkach and Kulozik, 2007). Nevertheless, kinetic descriptions cannot provide information regarding the evolution of particle sizes along the process unit. According to Bansal and Chen (2006), efforts remain to be accomplished in assessing the role of different types of aggregates on the fouling deposit formation, as well as in generalizing mitigation strategies. The evolution of particle sizes along the process unit can also be relevant to the sensory and rheological properties of products like yoghurt (Torres et al., 2011). 
The evolution of a suspension of beta-lactoglobulin under continuous thermal

51 treatment involves the occurrence of fluid flow, heat transfer and product transformation.

These processes are coupled: on one hand, the product transformation depends on the operation conditions (velocity, shear and temperature fields); on the other hand, the liquid food thermal and rheological properties are themselves modified as a result of the product transformation. Such a two-way dependence is put in evidence in Figure 1. The suspension flows along a tubular heat exchanger, which is represented by an axially-symmetric rectangular domain; the inlet and outlet are represented by the left and right sides of the domain, and the suspension is heated from the wall (bottom of domain).

In Figure 1a, it is assumed that fluid parcels move according to a plug-flow velocity field, and that they are exposed to a temperature field depending only on the distance from the exchanger inlet. Such a one-dimensional (1D) model, neglecting the radial dependence of both velocity and temperature, represents the simplest way to characterize the path to be followed by fluid parcels along a heat exchanger. At the inlet the suspension is assumed to contain monomers only. Upon exposure to heat the temperature of suspension can reach the threshold value for unfolding; after that, unfolded monomers can aggregate. At the outlet, the suspension contains remaining monomers and particles of different sizes resulting from aggregation. In Figure 1a, the resulting particle size distribution is characterized by a qualitative width A.

However, as shown in Figure 1b, one cannot neglect the fact that fluid parcels move slower near heating walls. Such fluid parcels undergo dynamical and thermal (and hence kinetic) histories in the process unit that are different from those associated with parcels running far from walls. As a consequence, the extension of unfolding and aggregation depends no longer on the distance from the exchanger inlet only, but on those histories experienced by each fluid parcel. The extension of the product transformation is therefore 
expected to increase towards the wall. Different size distributions can be obtained at the outlet, depending on the radial position (see Figure 1b); as a result, the bulk size distribution can be broader than that obtained with the $1 \mathrm{D}$ model (compare widths $\mathrm{A}$ and $\mathrm{B}$ ). The formation of larger particles allows an increase of the volume associated with the suspension solid fraction, which in turn can modify the suspension viscosity. Figure 1b puts in evidence the role played by dynamical and thermal histories experienced by fluid parcels, showing that both the velocity and the temperature depend on the radial distance. We argue that naive assumptions about fluid flow and heat transfer (like the 1D model, Figure 1a) can provide a biased picture regarding particle sizes at the heat exchanger outlet.

In order to realistically represent the denaturation-aggregation of beta-lactoglobulin under thermal treatment, we propose a numerical approach that combines computational fluid dynamics (CFD) for solving the fluid-flow and heat-transfer coupled problem, with a population balance equation (PBE) for evaluating particle aggregation. CFD has become an important tool for research and education in a number of subjects including food science and technology (Norton and Sun, 2006). For instance, CFD has been employed in looking for the optimal design of plate heat exchangers conceived for milk processing (Grijspeerdt et al., 2003). The PBE is a common model used to represent the evolution of particulates and dispersed-phase systems when nucleation, growth, aggregation or fragmentation (breakage) of particles occur (Marchisio and Fox, 2005). For instance, the PBE has been adapted in studying the breakage of whey protein precipitates under selected flow conditions (Zumaeta et al., 2007; Bas et al., 2009). Simulation strategies combining CFD and PBE approaches have became feasible with the increase of computation facilities, allowing a more detailed analysis of the particle, droplet or bubble's distribution along the fluid evolution (Marchisio and Fox, 2005; Bhole et al., 2008). In the scope of food science and technology, strategies 

summary and indicates future work. up to a selected level of convergence.

combining CFD and PBE have been implemented in studying the ice crystallization of sucrose solutions in scraped surface freezers (Lian et al., 2006).

In this exploratory study, our aim is to demonstrate that a more realistic representation of the thermal denaturation-aggregation of whey proteins, and particularly of the aggregation of particles under consideration, can be reached with an approach able to take into account the different dynamical and thermal histories associated with fluid parcels in the processing unit. The present approach combines the respective advantages of Eulerian and Lagrangian descriptions of fluid flow, focusing on the coupled representation of fluid flow, heat transfer and whey protein denaturation-aggregation processes. Fluid flow and heat transfer are solved through the finite element method in the Eulerian frame, while the product transformation is evaluated along Lagrangian trajectories associated with representative fluid parcels. Whey protein unfolding is represented by a reaction kinetics of order 1.5, while particle aggregation is assessed after discretization of the PBE. The impact of particle sizes on the suspension viscosity is estimated, allowing the update of the previous solution for fluid flow and heat transfer. The coupled problem is solved by iterating successive Lagrangian and Eulerian steps

The article is organized as follows. Section 2 presents how the processes of fluid flow, heat transfer, proteins unfolding and particle aggregation are modeled. Section 3 describes how the coupled problem is solved; particular attention is devoted to the solution of the PBE after its discretization, and to the coupling between the PBE solution and CFD results. Section 4 discusses relevant results from our Eulerian-Lagrangian approach, including a comparison with those obtained by neglecting the radial dependence of velocity and temperature fields along the heat exchanger (1D model). Finally, Section 5 provides a 


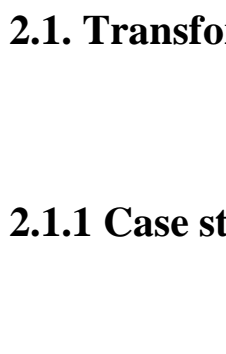
system. The coupled problem of fluid flow and heat transfer processes is solved on the whole domain using an Eulerian representation while the protein unfolding and particle aggregation are evaluated on a set of fluid parcels whose Lagrangian trajectories depends on the fluid velocity. Such a strategy allows the evaluation of transformation processes that cannot be easily coupled with CFD. This is the particular case of the evaluation of particle aggregation through the PBE approach by employing class or pivot methods, which represent the particle size distribution with the help of a number of size classes. 
149 which lead to a temperature increase from $50{ }^{\circ} \mathrm{C}$ (pre-heating temperature) to a maximum

150 value of about $110{ }^{\circ} \mathrm{C}$. Such a treatment allows a significant level of unfolding-aggregation

151 and could be achieved on a pilot plant for further comparison with experimental data.

152

153

\subsubsection{Protein unfolding}

154

155

The denaturation-aggregation of beta-lactoglobulin has been modeled using a reaction

kinetics (Anema and McKenna, 1996). The native protein concentration $C_{n a t}\left(\mathrm{~mol} . \mathrm{m}^{-3}\right)$ at

time $t$ is given by:

158

$159 \quad \frac{D C_{\text {nat }}\{t\}}{D t}=-k_{n} C_{\text {nat }}^{n}\{t\}$

160

161 where $n$ is the reaction order and $k_{n}$ is the rate constant of the reaction $\left(\left(\operatorname{mol} \cdot \mathrm{m}^{-3}\right)^{(1-\mathrm{n})} \cdot \mathrm{s}^{-1}\right)$. The reaction order $n$ may express the complexity of the unfolding sub-reactions, rather than the formal order of a classical chemical reaction; in the case of beta-lactoglobulin, it usually takes values between 1 and 2, commonly 1.5 (Tolkach and Kulozik, 2007). The relationship

165 between the rate constant and the temperature of the reaction is given by the Arrhenius 166 equation:

170 where $k_{0}$ is the frequency factor, $E_{a}$ the activation energy $\left(\mathrm{J} \cdot \mathrm{mol}^{-1}\right), R$ the universal gas

171 constant $\left(\mathrm{J}_{\mathrm{mol}}{ }^{-1} \cdot \mathrm{K}^{-1}\right)$ and $T$ the temperature (K). 
173 has put in evidence a marked change in temperature dependence of the reaction rate constant

174 at a threshold of about $85-90{ }^{\circ} \mathrm{C}$ (e.g., Lyster, 1970). As a matter of fact, such a behavior

175 results from the occurrence of two regimes: below the temperature threshold, the reaction is

176 limited by the unfolding sub-reactions; above that value, the reaction is limited by the 177 aggregation process (Tolkach and Kulozik, 2007).

In this study the thermal denaturation-aggregation of beta-lactoglobulin is represented as a two-step process. Firstly, a reaction kinetics is assumed in estimating the concentration of native proteins which undergo partial reversible unfolding; the temperature is assumed to be the only limiting factor. Secondly, the population balance equation is solved in order to estimate the final concentration of the particles which reach, via aggregation, a number of prescribed sizes. Limiting factors of this second step are the concentration of unfolded proteins, the temperature and the shear rate.

A reaction kinetics of order 1.5 is hereafter assumed in representing the thermal unfolding of the beta-lactoglobulin. Table 1 summarizes values of $k_{1.5}$ obtained by Anema and McKenna (1996) for two variants of beta-lactoglobulin under selected temperatures in

188 the range $70-85^{\circ} \mathrm{C}$. Looking for a more representative set of results, an unique Arrhenius 189 equation is assumed to characterize both variants. We estimated the frequency factor and the activation energy by fitting the data presented on Table 1 as a whole: 
196 These values are employed into equations (1) and (2) independently on the value assumed by

197 the temperature as computed by the numerical approach. For temperatures above $85{ }^{\circ} \mathrm{C}$ the

198 extrapolation of the Arrhenius equation can lead to under- or overestimate the unfolding rate,

199 but unfolding is then no more the limiting factor. Indeed, in our case study, unfolding times

200 rapidly decrease with the temperature ( 1 min at $85{ }^{\circ} \mathrm{C}, \sim 1 \mathrm{~s}$ at $\left.100{ }^{\circ} \mathrm{C}\right)$; unfolded protein

201 molecules are immediately engaged in the irreversible aggregation process which becomes

202 the limiting mechanism.

203

204

\subsubsection{Particle aggregation}

205

Once unfolded, the whey protein monomers are assumed to aggregate according to the

population balance equation proposed by Smoluchowski (1917). This kind of model has been used for a wide range of applications, including the aggregation of whey proteins (Wu et al., 2005; Péron et al.; 2007). After assuming no breakage of aggregates, the evolution of the number of particles containing $k$ monomers $\left(N_{k}\right)$ can be expressed as:

$$
\frac{D N_{1}\{t\}}{D t}=k_{1.5} C_{\text {nat }}^{1.5}\{t\} N_{A}-N_{1}\{t\} \sum_{\ell=1}^{M} Q_{1, \ell} N_{\ell}\{t\}
$$

$$
\frac{D N_{k}\{t\}}{D t}=\frac{1}{2} \sum_{\ell=1}^{k-1} Q_{k-\ell, \ell} N_{\ell}\{t\} N_{k-\ell}\{t\}-N_{k}\{t\} \sum_{\ell=1}^{M} Q_{k, \ell} N_{\ell}\{t\}
$$

215 in the cases $k=1$ and $k>1$, respectively, where $N_{l l}\{t\}$ is the number of unfolded monomers

216 at time $t, M$ the maximum number of monomers in an aggregate and $N_{A}$ the Avogadro 
218 phase viscosity $\left(\eta_{w}\right)$, on the shear rate $(\dot{\gamma})$ (Pa.s), and finally on the radii $a_{k}$ and $a_{l}$ of the aggregates under consideration:

$$
Q_{k, \ell}=\frac{2}{3} \frac{k_{B}}{W} \frac{T}{\eta_{w}} \frac{\left(a_{k}+a_{\ell}\right)^{2}}{a_{k} a_{\ell}}+\frac{4}{3} \frac{\dot{\gamma}}{W}\left(a_{k}+a_{\ell}\right)^{3}
$$

where $k_{B}$ is the Boltzmann constant and $\mathrm{W}$ the Fuchs stability factor. The radius $a_{k}$ of an aggregate containing $k$ monomers can be estimated from the monomer radius $a_{k}$ and the aggregates fractal dimension $(D)$ :

The fractal dimension describes the microstructure of the aggregates (Bremer et al., 1989), allowing to link the number of monomers in an aggregate with its size. This parameter depends on the monomer / continuous phase couple as well as on the operating conditions (Byrne et al., 2002).

In this exploratory study we focus the attention on the aggregation of betalactoglobulin molecules. Under the considered conditions ( $\mathrm{pH}=6.8$ and $0.1 \mathrm{M} \mathrm{NaCl}$ ), betalactoglobulin monomers exhibit a globular hydrodynamic radius $\left(a_{0}\right)$ of about $2 \mathrm{~nm}$ (Aymard et al., 1996). Under quite similar conditions, comparisons between measurements and 237 numerical PBE solutions have suggested the value $W=91$ for the Fuchs stability factor 238 (Elofsson et al. 1996). Still under those conditions, the combination of permeability, 239 rheology, and aggregation kinetics measurements on whey protein gels has indicate the value $D=2.4$ for the aggregates fractal dimension (Verheul et al., 1998). 
Taking into account the concentration of 3.2 g. $\mathrm{L}^{-1}$, the initial suspension contains

$2421.053110^{23}$ monomers per cubic meter. For a maximum total volume fraction of 0.6, 243 corresponding to the random packing, the largest aggregates should have a radius of about 10 $244 \mu \mathrm{m}$ and should contain about $M=10^{9}$ monomers.

\subsection{Fluid flow and heat transfer models}

\subsubsection{Mass, momentum and energy conservation}

$\rho(\mathbf{v} \cdot \nabla) \mathbf{v}=\nabla\left(-p \cdot \mathbf{I}+\eta\left(\nabla \mathbf{v}+(\nabla \mathbf{v})^{T}\right)\right)$

255

$\rho C_{P}(\mathbf{v} \cdot \nabla) T=\nabla \cdot(\lambda \nabla T)$

Coupled phenomena are illustrated inside a tubular heat exchanger with length $1 \mathrm{~m}$

and radius $5 \mathrm{~mm}$, which is represented through a two-dimension axial-symmetric domain. A

liters per hour (mean velocity $0.0351 \mathrm{~m} . \mathrm{s}^{-1}$ ). A uniform flux of $10 \mathrm{~kW} \cdot \mathrm{m}^{-2}$ is applied on the heating wall, and the temperature associated with the suspension is assumed to be $50{ }^{\circ} \mathrm{C}$ at the inlet. These conditions enable temperatures of about $110^{\circ} \mathrm{C}$ at the outlet near the heating

264 wall. Such a temperature enables a relevant degree of protein unfolding and particle 
265

266

267

268

269

270

271

272

273

274

275

276

277

278

279

280

281

282

283

284

285

286

287

\section{8}

aggregation (Tolkach and Kulozik, 2007; de Wit, 2009). According to the Reynolds number, the flow regime is laminar. Boundary conditions are summarized in Figure 2.

\subsubsection{Suspension viscosity}

The liquid food product under consideration is an aqueous suspension of whey proteins. The apparent viscosity $\eta$ associated with the suspension is obtained by multiplying the continuous phase (pure water) viscosity $\eta_{W}$ and the relative viscosity $\eta_{R}$ which is a function of the transformation state. Pure water viscosity depends on the local temperature, and such an influence can be evaluated through a reference formulation (IAPWS, 2008):

$$
\eta_{W}=10^{-6}\left(280.68\left(\frac{T}{300}\right)^{-1.9}+511.45\left(\frac{T}{300}\right)^{-7.7}+61.131\left(\frac{T}{300}\right)^{-19.6}+0.45903\left(\frac{T}{300}\right)^{-40}\right)
$$

Various approximations have been proposed for estimating the relative viscosity as a function of the volume fraction $(\Phi)$ occupied by the particles under consideration. We have retained the model proposed by Thomas (1965),

$$
\frac{\eta}{\eta_{W}}=\eta_{R}=1+2.5 \Phi+10.05 \Phi^{2}+0.00273 \exp (16.6 \Phi)
$$


$\Phi=\frac{4 \pi}{3} \sum_{k=1}^{M} N_{k}\{t\} a_{k}^{3}$

\section{Problem solving}

\subsection{Population balance equation resolution}

Once unfolded, the beta-lactoglobulin is subjected to aggregation, represented by the population balance equation. Its resolution by equation (5) involves the calculation of the population of a very large number of aggregates size, as an aggregate can contains up to $10^{9}$ monomers. In order to reduce the computational cost, only a limited number of pivots, indexed by $i$ or $j$, are here considered. This approach has been used by Batterham et al. (1981) and Hounslow et al. (1988); the latter computed the size distribution of kidney stones by considering only the particles whose volume is on a regular grid described by $V_{i+1} / V_{i}=2$. This approach can be applied to proteins aggregation by considering the monomers number of a particle instead of its volume. Here, a monomer number grid is used with $n_{i+1} / n_{i}=2$, where $n_{i}$ is the number of monomers in the aggregates of pivot $i$. The aggregates of the pivots $i$ hence contain $n_{i}=2^{i-1}$ monomers. Figure 3 displays an example of population balance and its repartition on such a pivot grid.

As expected, the conservation of quantities such as the total mass or the total number of particles may be problematic. To solve this issue, (Kumar and Ramkrishna, 1996) showed that some conditions can lead to the conservation of several quantities using only a reduced set of pivots.

For instance, in the case of the aggregation of particles of size $k=2$ and $l=8$ (as shown on Figure 4), the resulting particle contains 10 monomers and thus, is not among the calculated pivots. In order to take its presence into account, the number of particles in the two 


$$
\frac{d N_{i}\{t\}}{d t}=N_{i-1}\{t\} \sum_{j=1}^{i-2} 2^{j-i+1} Q_{i-1, j} N_{j}\{t\}+\frac{1}{2} Q_{i-1, j-1} N_{i-1}^{2}\{t\}-
$$

$$
-N_{i}\{t\} \sum_{j=1}^{i-1} 2^{j-i} Q_{i, j} N_{j}\{t\}-N_{i}\{t\} \sum_{j=i}^{M} Q_{i, j} N_{j}\{t\}
$$

For the general case of equation 14b, the first term accounts for the creation of aggregates on the pivot $i$ by aggregation of aggregates from pivot $i-1$ with smaller ones, whereas the second term accounts for the creation of aggregates on pivots $i$ by aggregation of two aggregates from pivot $i$-1. The last two terms described the destruction of aggregates on pivot $i$ by aggregation with either smaller (third term) or larger (last term) aggregates. The number of pivots is limited to $M=30$, corresponding to aggregates of radius about $10 \mu \mathrm{m}$. 


\subsection{Coupling of fluid flow, heat transfer and product transformation by an Eulerian-}

\section{Lagrangian approach}

A schematic diagram of the approach is presented in Figure 5. The liquid food is assumed flowing in a tubular heat exchanger, which is represented by a rectangular domain.

The dashed red and the bold black lines indicate the axis of symmetry and the heating wall, while the left and right sides represent the domain inlet and outlet respectively. Fluid parcels running nearer to the heating wall move slower than those at the axis; therefore dynamical and thermal histories differ accordingly, leading to different transformation state evolution along their trajectories.

The present study combines the respective advantages of Eulerian and Lagrangian descriptions of fluid flow. Fluid flow and heat transfer are solved through the finite element method in the Eulerian frame, while the product transformation is evaluated along Lagrangian trajectories associated with representative fluid parcels.

Before the first iteration, a preliminary modeling of fluid flow and heat transfer is needed. It provides a first estimate of the velocity, shear rate and temperature fields along the Eulerian frame. Because this modeling step is performed before any product transformation,

354 the viscosity is here assumed to be the one of the continuous phase (pure water). Eulerian modeling of fluid flow and heat transfer is solved by using a mesh constituted of 100 rectangles along the domain's radius and 2000 rectangles along the length.

The first step of a given iteration is the estimation of Lagrangian trajectories 358 associated with a number of representative fluid parcels. Each trajectory is defined by a 359 number of positions, and each of them is associated with a given time since the fluid parcel 360 release at the domain inlet. The estimation of trajectory positions from the Eulerian velocity 
field is performed with the help of a routine implementing a fourth-order Runge-Kutta method (Abramowitz and Stegun, 1972). After a number of sensitivity tests, we found satisfactory the application of 200 trajectories with about 200 positions on each.

In the second step, Lagrangian trajectories are employed in the reconstruction of dynamical and thermal histories along the domain. Each history is described by a series of positions, times, and the values associated with the shear rate and temperature. These values are estimated from the last available Eulerian respective fields.

Next, the shear rate and temperature histories are employed, along every trajectory, in evaluating the protein unfolding degree (eqs. 1 and 2) and in solving the PBE (eqs. 6 and 14). This is the key step regarding the flexibility of the Eulerian-Lagrangian approach proposed: any available methodology can be employed in evaluating the degree of transformation of the liquid food product along the process unit. The availability of the particle size distribution enables the evaluation of the volume fraction associated with the solid fraction (eq. 13), which is then used for estimating the suspension viscosity (eq. 12).

Updated suspension viscosity values have to be informed to the Eulerian model, as a previous task towards an updated solution for the fluid flow and heat transfer problem. Difficulties at this step come from the fact that Lagrangian trajectories provide updated viscosity values at a number of positions which are irregularly distributed along the Eulerian frame. The Delaunay triangulation was retained as strategy. The application of constraints relying successive positions along a same trajectory proves useful. As a result, the suspension viscosity values available at Lagrangian positions are successfully interpolated into a suspension viscosity field needed at the nodes constituting the Eulerian frame.

Before the following iteration, a new Eulerian modeling of fluid flow and heat transfer is performed. It provides updated fields for the velocity, shear rate and temperature. Because this modeling step is performed by taking into account an improved suspension 
viscosity field, it is expected that these velocity, shear rate and temperature fields represent a somewhat better picture of the fluid flow and heat transfer conditions under the occurrence of product transformation.

The coupled problem is solved by iterating the successive Lagrangian and Eulerian steps up to a selected level of convergence. The solution is assumed to be reached when successive viscosity fields exhibit a maximum difference smaller than $0.25 \%$.

This algorithm was implemented through a main program and a set of functions developed in the programming language MATLAB. Eulerian modeling of fluid flow and heat transfer was solved with the help of the COMSOL Multiphysics 3.5a simulation package, using the UMFPACK solver. The implementation of both tasks, including the adoption of other mathematical solvers, seems feasible in other programming languages.

\subsection{One-dimensional model}

The transformation of liquid food product under heat treatment has been often represented in the literature by considering average temperature evolution along the exchanger and by assuming plug flow. In this case, both the velocity and temperature fields are assumed to be independent on the distance from the heating wall (e.g., Grijspeerdt et al. (2004)). Such an one-dimensional (1D) model is included in the present study for the sake of comparison with a more elaborate approach, in which no assumptions are performed regarding the velocity and temperature fields.

Coherently with the application of the Eulerian-Lagrangian approach, the evaluation of the thermal denaturation-aggregation of beta-lactoglobulin requires the unfolding rate constant, (eq. 2) and the aggregation kernel (eq. 6), whose computation asks for local estimates of temperature and shear rate. In the scope of the 1D model, bulk values are used. 
$412\left(\mathrm{~W} \cdot \mathrm{m}^{-2}\right)$, the heat balance for a tubular exchanger can be expressed as:

413

$414 \rho \bar{v} \pi R^{2} C_{P} d \bar{T}=2 \pi R Q d z$

415

416 where $\rho\left(\mathrm{kg} \cdot \mathrm{m}^{-3}\right)$ is the product density, $\bar{v}\left(\mathrm{~m} . \mathrm{s}^{-1}\right)$ the plug-flow velocity, $R(\mathrm{~m})$ the radius of

417 the exchanger, $C_{P}$ the specific heat capacity $\left(\mathrm{J} \mathrm{kg}^{-1} \cdot \mathrm{K}^{-1}\right)$ and $\bar{T}(\mathrm{~K})$ the bulk temperature.

418 The integration of equation (15) provides the bulk temperature as a function of the 419 distance from the exchanger inlet:

420

$421 \quad \bar{T}\{z\}=T_{\text {inlet }}+\frac{Q}{2 \rho \bar{v} R C_{P}} z$

422

423

A first-order estimate of the shear rate bulk value required for evaluating particle

424 aggregation in the $1 \mathrm{D}$ model may be obtained from the parabolic flow profile. At a given 425 radial distance $r$ from the axis of symmetry of the tubular exchanger, the shear rate associated

426 with parabolic flow can be expressed as:

427

$428 \quad \dot{\gamma}\{r\}=\frac{4 \bar{v}}{R^{2}} r$

429

430 Its bulk value is therefore given by:

431

$432 \quad \overline{\dot{\gamma}}=\frac{\int \dot{\gamma}\{r\} v\{r\} d S}{\int v\{r\} d S}=\frac{32 \bar{v}}{15 R}$ 
434 Taking into account the geometry and boundary conditions defined above $(\mathrm{R}=5 \mathrm{~mm}$ and $\bar{v}$ $435=0.0354 \mathrm{~m} . \mathrm{s}^{-1}$ ), we obtain $\overline{\dot{\gamma}}=15.1 \mathrm{~s}^{-1}$.

436 After estimating bulk values for both the temperature and the shear rate, the 437 evaluation of the thermal denaturation-aggregation of beta-lactoglobulin can hence be 438 performed by employing bulk values for both the temperature and the shear rate. For 439 instance, equation (1) can be rewritten as:

440

441

$\frac{D C_{\text {nat }}\{t\}}{D t}=\bar{v}\{z\} \frac{d C_{\text {nat }}\{z\}}{d t}=-k_{n}\{z\} C_{\text {nat }}^{n}\{z\}$

\section{Results}

\subsection{Fluid flow and temperature}

Figure 6 shows the velocity, temperature, suspension viscosity and shear rate fields resulting from the simulations described above.

The velocity field (Figure 6a) is assumed as a fully developed flow (parabolic profile) at the domain inlet. The velocity at the exchanger axis (top of domain) firstly slightly decreases along the first $30 \%$ of the tube length, and then increases up to the outlet where it reaches higher values than at the inlet. Near the heating wall, fluid parcels move slower. Moreover, the region associated with relatively low velocities is broader near the outlet than 454 at the inlet.

Figure $6 \mathrm{~b}$ shows that temperatures increase along the domain as a consequence of the 456 developing thermal boundary layer from the heating wall towards the exchanger center. 
Figure 6c shows that the suspension viscosity increases near the heating wall along the domain, reaching values many times higher near the outlet than that observed at the inlet; moreover, the region associated with increasing suspension viscosity becomes progressively broader along the domain. The latter result is consistent with the decrease of the axial velocity near the heating wall (see Figure 6a).

At the domain inlet, the shear rate is proportional to the distance from the exchanger axis as a consequence of the fully-developed incoming flow. However, the shear rate field displayed on the Figure 6d denotes 3 regions: weak values near the exchanger center, b) low values at the wall after an initial increase, and c) between these two patterns, progressively increasing values in a ridge-like region that appears after about $20 \%$ of the exchanger length from the inlet. The first feature is consistent with the symmetry of the velocity profile at the exchanger axis, while the second feature is consistent with the weak velocities occurring in the region near the wall which becomes broader along the domain. The ridge-like pattern with higher shear rates is a consequence of previous features.

\subsection{Product transformation along trajectories}

The evolution of the product properties will be analysed along Lagrangian trajectories associated with fluid parcels released at the domain inlet. Each fluid parcel can be considered as a suspension droplet containing an ensemble of whey protein particles at similar thermodynamic and kinetic conditions.

Figure 6a displays the five trajectories hereafter taken into account, each of them associated with a given radial release positions at the domain inlet $\left(r_{0}\right)$. These distances were chosen in order to sample different regions of the domain: firstly the exchanger axis, where the highest velocity as well as the minimum transformation are expected $\left(r_{0}=0\right)$; then the 
482

483

484

485

486

487

488

489

490

491

492

493

494

495

496

497

498

499

500

501

502

503

504

505

506

average radial position $\left(r_{0}=2.5 \mathrm{~mm}\right)$; and finally three release positions progressively closer to the heating wall $\left(r_{0}=4,4.5\right.$, and $\left.4.75 \mathrm{~mm}\right)$.

Figure $7 \mathrm{a}$ presents the temperature evolution along these five trajectories, the residence time values from 13.8 up to 174 seconds are indicated on the right. Fluid parcels move slower as they run closer to the wall, being therefore more exposed to heating. Coherently, outlet temperatures increase with $r_{0}$.

The evolution of shear rate along these trajectories is displayed in Figure 6b. The shear rate is null on the axis and presents maximum values for the fluid parcels which are moving in the vicinity of the heating wall. The behavior of the two trajectories closest to the wall ( $r_{0}=4.5$ and $4.75 \mathrm{~mm}$ ) indicates first an increase, and then a decrease towards the outlet. The maximum values are associated with the ridge-like feature appearing in Figure 6d. Fluid parcels released near the middle of the domain $\left(r_{0}=2.5\right.$ and $\left.4 \mathrm{~mm}\right)$ are associated with simpler shear rate evolutions as they do not enter in the ridge-like region.

Temperature drives the unfolding kinetics (eqs. 1-2), and drives together with the shear rate the aggregation by modifying the aggregation kernel (eq. 6). As shown in Figure 7, these two key variables exhibit different evolutions along the domain from a trajectory to another. One can therefore expect different unfolding/aggregation histories along the domain under consideration, implying different whey protein particle size distributions at the outlet.

Figure 8 presents the evolution of the unfolding ratio -- that is the percentage of proteins that have been unfolded; the volume fraction associated with whey protein aggregates $(\Phi)$ and the Sauter mean diameter $\left(d_{3,2}\right)$.

The liquid food product transformation is negligible for fluid parcels moving on the axis $\left(r_{0}=0 \mathrm{~mm}\right)$ as well as for those released at the average radial position $\left(r_{0}=2.5 \mathrm{~mm}\right)$. This is a consequence of the negligible whey protein unfolding because of the relatively low temperatures experienced along these two trajectories (see Figure 7a). 
On the other hand, fluid parcels moving in the vicinity of the heating wall ( $r_{0}=4.75$

508

509

510

511

512

513

514 $\mathrm{mm}$ ) experience almost complete unfolding after about $80 \%$ of the exchanger length as displayed on Figure 8a. Such a high level of product transformation results from the fast temperature increase over $70{ }^{\circ} \mathrm{C}$. For $r_{0}=4.75 \mathrm{~mm}$, shear rate is also relatively high along the first $60 \%$ of the trajectory as depicted on Figure $7 \mathrm{~b}$; these conditions provide favorable conditions to aggregation. This results in a large increase of the Sauter diameter (Figure 8b) and of the volume fraction of the aggregates. The solid volume fraction increases up to $40 \%$ and the Sauter diameter becomes more than 2000 times larger than its value at the inlet. Intermediate behaviors are exhibited by trajectories associated with fluid parcels released between $r_{0}=2.5$ and $4.75 \mathrm{~mm}$.

\subsection{Viscosity evolution}

The suspension viscosity is driven by the continuous phase (pure water) viscosity as well as by the volume fraction of particles in suspension. Figure 9 shows that the suspension viscosity can appreciably vary along the domain; moreover it can be very different from a given trajectory to another.

Fluid parcels moving at the exchanger axis $\left(r_{0}=0\right)$ and those released at the average radial position $\left(r_{0}=2.5 \mathrm{~mm}\right.$ ) are associated with negligible product transformation (see Figure 8). The suspension viscosity decreases along these trajectories, indicating the role of increasing temperature on the continuous phase viscosity.

On the other hand, fluid parcels moving closer to the heating wall $\left(r_{0}=4.5\right.$ and 4.75 $\mathrm{mm}$ ) experience both a meaningful heating and a high level of product transformation. As a result, the suspension viscosity along these trajectories exhibits a two steps behavior (see Figure 9). On the first half of the exchanger, the suspension viscosity decreases (because 
continuous phase viscosity is lower for higher temperatures). Then, the product is

533 transformed and aggregation occurs; it involves the increase of the suspension viscosity

534 because that the influence of the growing aggregates volume fraction overtakes the 535 temperature effect on the continuous phase.

\subsection{Product properties at the outlet}

After one meter of exchanger, the output product is subjected to a broad diversity due

to the different time-temperature-shear rate histories. Figure 10a displays the cumulative

volume distribution of the monomers and aggregates at the domain outlet for five selected trajectories.

For the two inner fluid parcels ( $r_{0}=0$ and $2.5 \mathrm{~mm}$ ), the aggregation is negligible, the monomers account for more than $98 \%$ of the total volume. The trajectory starting at $r_{0}=4$ $\mathrm{mm}$ still contains a large number of monomers, but they account only for $6 \%$ of the solid volume.

For the fluid parcels starting from $r_{0}=4.5$ and $4.75 \mathrm{~mm}$ all the proteins are aggregated 548 (no monomer remains). One can sum up that the closer the trajectory is to the heating wall, 549 the higher is the median diameter.

Figure 10b displays the particle size distribution of the output bulk product. The output product described using the 2-D Eulerian-Lagrangian model is a blend of the different

552 fluid parcels which a sample is displayed on Figure 10a. Consequently, a large number of 553 monomers averagely remains, they account for $14 \%$ of the solid volume The bulk median 554 radius value is about $1 \mu \mathrm{m}$ with broad particle size distribution: $20 \%$ of the solid volume is constituted by particles smaller than $0.2 \mu \mathrm{m}$ and $30 \%$ by particles larger than $5 \mu \mathrm{m}$. 


\subsection{Comparison with 1D model results}

We have argued in the Introduction and shown previously that thermal and dynamic histories can affect the transformation state of the liquid food product.

Table 2 presents the product properties at the outlet for both the $2 \mathrm{D}$ and the $1 \mathrm{D}$ model. The first line displays the ranges of values assumed by selected variables at the domain outlet ( $r$ varying from 0 up to $R=5 \mathrm{~mm}$ ), as provided by our 2D simulations. Such ranges are very large, clearly putting in evidence the variety of dynamic and thermal histories experienced by fluid parcels.

The following lines in Table 2 present the bulk properties of the output product, that is the properties of the fluid obtained by mixing all the outcoming fluid parcels. These values are those of industrial process interest.

Bulk values are far from those associated with fluid parcels released at the average radial position, as shown in the third line of Table 2 . This 'average' trajectory $\left(r_{0}=2.5 \mathrm{~mm}\right)$ is thus not representative for the process.

Last line in Table 2 displays corresponding results provided by the 1 -D model described above. This model does not represent the variety of conditions experienced by the liquid food product along the exchanger. It provides essentially the same results as those obtained for fluid parcels released at the average radial position $\left(r_{0}=2.5 \mathrm{~mm}\right)$. The results are clearly different from the bulk estimated with the more realistic 2D coupled model.

\section{Conclusion}

Thermal denaturation of beta-lactoglobulin in a tubular exchanger has been modeled using a 2D Eulerian/Lagrangian numerical scheme. By splitting the fluid flow and heat 
582

583

584

585

586

587

588

589

590

591

592

593

594

595

596

597

598

599

600

601

602

603

604

605

\section{References}

606 structure.

604

transfer model from the transformation determination, a realistic population balance model can be used to estimate the proteins aggregation.

The results show the diversity of the output product properties depending on the timetemperature-shear rate histories of the different flow parts: in the region near the wall, the product is heavily heated for a long time, resulting in largely modified product; in the axial region, where the temperature is relatively low and the residence time is shorter, the product is weakly modified.

The described numerical approach takes into account the diversity of dynamic and thermal histories experienced by fluid parcels along different trajectories in contrary to the approach where the product is considered as a whole. Indeed, comparison with a simple 1D model shows that bulk properties of the outlet product cannot be predicted in this case without a 2D fully coupled approach.

The use of the Eulerian/Lagrangian approach allows the implementation of complex transformation models, as often necessary when dealing with food processing modeling, without the need of oversimplification or model rewriting to comply with the CFD solver

\section{Acknowledgement}

The research leading to these results has received funding from the European Community's Seventh Framework Program (FP7/ 2007-2013) under the grant agreement nFP7-222 654-DREAM. 
607

608

609

610

611

612

613

614

615

616

617

618

619

620

621

622

623

624

625

626

627

628

629

630

Abramowitz, M., \& Stegun, I.A. (Eds.) (1972). Handbook of Mathematical Functions, with Formulas, Graphs, and Mathematical Tables. Dover Publications, New York.

Anema, S.G., \& McKenna, A.B. (1996). Reaction kinetics of thermal denaturation of whey proteins in heated reconstituted whole milk. Journal of Agricultural and Food Chemistry, 44, 422-428.

Aymard, P., Durand, D., \& Nicolai, T. (1996). The effect of temperature and ionic strength on the dimerisation of beta-lactoglobulin. International Journal of Biological Macromolecules, 19, 213-221.

Bansal, B., \& Chen, X.D. (2006). A critical review of milk fouling in heat exchangers. Comprehensive Reviews in Food Science and Food Safety, 5, 27-33.

Bas, N., Catak, M., Zumaeta, N., Fitzpatrick, J.J., Cronin, K., \& Byrne, E.P. (2009). Population balance modelling of protein precipitates exhibiting turbulent flow through a circular pipe. Chemical Engineering Science, 64, 4051-4059.

Batterham, R.J., Hall, J.S., \& Barton, G. (1981). Pelletizing kinetics and simulation of fullscale balling circuits. Preprints of the Third International Symposium on Agglomeration, Nürnberg, Germany.

Bhole, M.R., Joshi, J.B., \& Ramkrishna, D. (2008). CFD simulation of bubble columns incorporating population balance modeling. Chemical Engineering Science, 63, 22672282.

Bremer, L.G.B., van Vliet, T., \& Walstra, P. (1989). Theoretical and experimental study of the fractal nature of the structure of casein gels. Journal of the Chemical Society, Faraday Transactions, 1, 85, 3359-3372.

Byrne, E.P., Fitzpatrick, J.J., Pampel, L.W., \& Titchener-Hooker, N.J. (2002). Influence of shear on particle size and fractal dimension of whey protein precipitates: implications 
for scale-up and centrifugal clarification efficiency. Chemical Engineering Science,

632 57, 3767-3779.

633

634

635

636

637

638

639

640

641

642

643

644

645

646

647

648

649

650

651

652

653

654

655

De Wit, J.N. (1998). Nutritional and functional characteristics of whey proteins in food products. Journal of Dairy science, 81, 597-608.

De Wit, J.N. (2009). Thermal behaviour of bovine beta-lactoglobulin at temperatures up to $150{ }^{\circ} \mathrm{C}$. A Review. Trends in Food Science and Technology, 20, 27-34.

Elofsson, U.M., Dejmek, P., \& Paulsson, M.A. (1996). Heat-induced aggregation of betalactoglobulin studied by dynamic light scattering. International Dairy Journal, 6, 343-357.

Grijspeerdt, K., Hazarika, B., \& Vucinic, D. (2003). Application of computational fluid dynamics to model the hydrodynamics of plate heat exchangers for milk processing. Journal of Food Engineering, 57, 237-242.

Grijspeerdt, K., Mortier, L., De Block, J., \& Van Renterghem (2004). Applications of modelling to optimise ultra high temperature milk heat exchangers with respect to fouling. Food Control, 15, 117-130.

Hounslow, M. J., Ryall, R. L., Marshall, V. R. (1988). A discretized population balance for nucleation, growth, and aggregation. American Institute of Chemical Engineers Journal, 34, 1821-1832.

IAPWS (2008). Supplementary Release on Properties of Liquid Water at 0.1 MPa. The International Association for the Properties of Water and Steam, Berlin, Germany.

Janhoj, T., Petersen, C.B., Frost, M.B., \& Ipsen, R. (2006). Sensory and rheological characterization of low-fat stirred yoghurt. Journal of Texture Studies, 37, 276-299.

Kumar, S., Ramkrishna, D. (1996). On the solution of population balance equations by discretization -I. A fixed pivot technique. Chemical Engineering Science, 51, 13111332. 
Lian, G., Moore, S., \& Heeney, L. (2006). Population balance and computational fluid dynamics modelling of ice crystallisation in a scraped surface freezer. Chemical Engineering Science, 61, 7819-7826.

Lyster, R.L.J. (1970). The denaturation of alpha-lactalbumin and beta-lactoglobulin in heated milk. Journal of Dairy Research, 37, 233-243.

Marchisio, D.L., \& Fox, R.O. (2005). Solution of population balance equations using the direct quadrature method of moments. Journal of Aerosol Science, 36, 43-73.

Navarra, G., Leone, M., \& Militello, V. (2007). Thermal aggregation of $\beta$-lactoglobulin in presence of metal ions. Biophysical Chemistry, 131, 52-61.

Norton, T., \& Sun, D.-W. (2006). Computational fluid dynamics (CFD) - an effective and efficient design and analysis tool for the food industry: A review. Trends in Food Science \& Technology, 17, 600-620.

Péron, N., Heffernan, S.P., Byrne, E.P., Rioual, F., \& Fitzpatrick, J.J. (2007). Characterization of the fragmentation of protein aggregates in suspension subjected to flow. Chemical Engineering Science, 62, 6440-6450.

Sawyer, L., \& Kontopidis, G. (2000). The core lipocalin, bovine beta-lactoglobulin. Biochimica et Biophysica Acta (BBA) - Protein Structure and Molecular Enzymology, $1482,136-148$.

Smoluchowski, M. (1917). Versuch einer mathematischen theorie der koagulationskinetik kolloider lösungen. Zeitschrift für Physikalische Chemie, 92, 129-168.

Swaisgood, H.E. (1995). Protein and amino acid composition of bovine milk. in Handbook of Milk Composition (R. G. Jensen, Ed.; Academic Press), pp.464-468.

Thomas, D.G. (1965). Transport characteristics of suspension: VIII. A note on the viscosity of Newtonian suspensions of uniform spherical particles. Journal of Colloid Science, 20, 267-277. 
681

682

683

684

685

686

687

688

689

690

691

692

693

694

695

696

697

698

699

700

701

Tolkach, A., \& Kulozik, U. (2007). Reaction kinetic pathway of reversible and irreversible thermal denaturation of beta-lactoglobulin. Lait, 87, 301-315.

Torres, I.C., Janhoj, T., Mikkelsen, B.O., Ipsen, R. (2011). Effect of microparticulated whey protein with varying content of denaturated protein on the rheological and sensory characteristics of low-fat yoghurt. International Dairy Journal, 21, 645-655.

Verheul, M., Roefs, S.P.F.M., Mellema, J., \& de Kruif, K.G. (1998). Power Law Behavior of Structural Properties of Protein Gels. Langmuir, 14, 2263-2268.

Wang, L., \& Sun, D.-W. (2006). Heat and mass transfer in thermal food processing, In D.-W. Sun (Ed.), Thermal Food Processing: New Technologies and Quality Issues (pp. 3571). Boca Raton: CRC press.

Wu, H., Xie, \& J., Morbidelli, M. (2005). Kinetics of cold-set diffusion-limited aggregations of denatured whey protein isolate colloids. Biomacromolecules, 6, 3189-3197.

Zumaeta, N., Byrne, E.P., \& Fitzpatrick, J.J. (2007). Predicting precipitate breakage during turbulent flow through different flow geometries. Colloids and Surfaces A: Physicochemical and Engineering Aspects, 292, 251-263.

\section{List of tables}

Table 1: Chemical kinetics parameters from Anema and McKenna (1996).

Table 2: Selected variables at the domain outlet. 


\begin{tabular}{|c|c|c|}
\cline { 2 - 3 } \multicolumn{1}{c|}{} & $\mathrm{T}\left[{ }^{\circ} \mathrm{C}\right]$ & $\begin{array}{c}\mathrm{k}_{1.5} \cdot{ }^{-3} \\
{\left[\left(\mathrm{~mol}^{-3}\right)^{-0.5} \cdot \mathrm{s}^{-1}\right]}\end{array}$ \\
\hline \multirow{4}{*}{$\beta$-lactoglobulin A } & 70 & $4.4010^{-4}$ \\
\cline { 2 - 3 } & 75 & $2.3110^{-3}$ \\
\cline { 2 - 3 } & 80 & $1.0810^{-2}$ \\
\cline { 2 - 3 }$\beta$ & 85 & $2.6810^{-2}$ \\
\hline \multirow{4}{*}{$\beta$-lactoglobulin B } & 70 & $3.6010^{-4}$ \\
\cline { 2 - 3 } & 75 & $2.6210^{-3}$ \\
\cline { 2 - 3 } & 80 & $1.4610^{-2}$ \\
\cline { 2 - 3 } & 85 & $3.9610^{-2}$ \\
\hline
\end{tabular}




\begin{tabular}{|l|c|c|c|c|}
\hline & $\begin{array}{c}\text { Unfolding ratio } \\
{[\%]}\end{array}$ & $\begin{array}{c}\text { Sauter diameter } \\
{[\mathrm{m}]}\end{array}$ & $\begin{array}{c}\text { particle volume } \\
\text { fraction [\%] }\end{array}$ & $\begin{array}{c}\text { number concentration } \\
\left.\text { [part } / \mathrm{m}^{3}\right]\end{array}$ \\
\hline 2-D (range) & 0 to $100 \%$ & $2.010^{-9}$ to $8.610^{-6}$ & 0.35 to 53.62 & $2.4110^{14}$ to $1.05310^{23}$ \\
\hline 2-D (bulk) & 14.1 & $1.510^{-8}$ & 2.35 & $9.0510^{22}$ \\
\hline 2-D (r $\left.\mathrm{r}_{0}=2.5 \mathrm{~mm}\right)$ & 0.1 & $2.010^{-9}$ & 0.35 & $1.05210^{23}$ \\
\hline 1-D model & 0.7 & $2.110^{-9}$ & 0.36 & $1.04610^{23}$ \\
\hline
\end{tabular}


2

3

4 simple 1D approach; (b) coupled 2 D approach.

5

6 Figure 2: Numerical domain and boundary condition.

7

8

9

10

11

12

13

14

15

Figure 9: Evolution of suspension viscosity along the fluid parcel trajectories.

Figure 4: Particles repartition along pivots after aggregation.

Figure 5: Iterative procedure.

Figure 6: Velocity (a), temperature (b), viscosity (c), and shear rate (d) fields on the domain.

Domain inlet and outlet are on the left and right respectively, and the heating wall is on the bottom. Five trajectories associated with fluid parcels released at the domain inlet are illustrated with the axial velocity field (a).

Figure 7: Evolution of temperature (a) and shear rate (b) along fluid parcels trajectories.

Figure 8: Evolution of unfolding ratio (a), Sauter diameter (b), and aggregate volume fraction (c) along the fluid parcels trajectories. 
26 Figure 10: Cumulative volume distribution of monomers and aggregates at the outlet for: a)

27 five selected trajectories, b) bulk product. 
a)

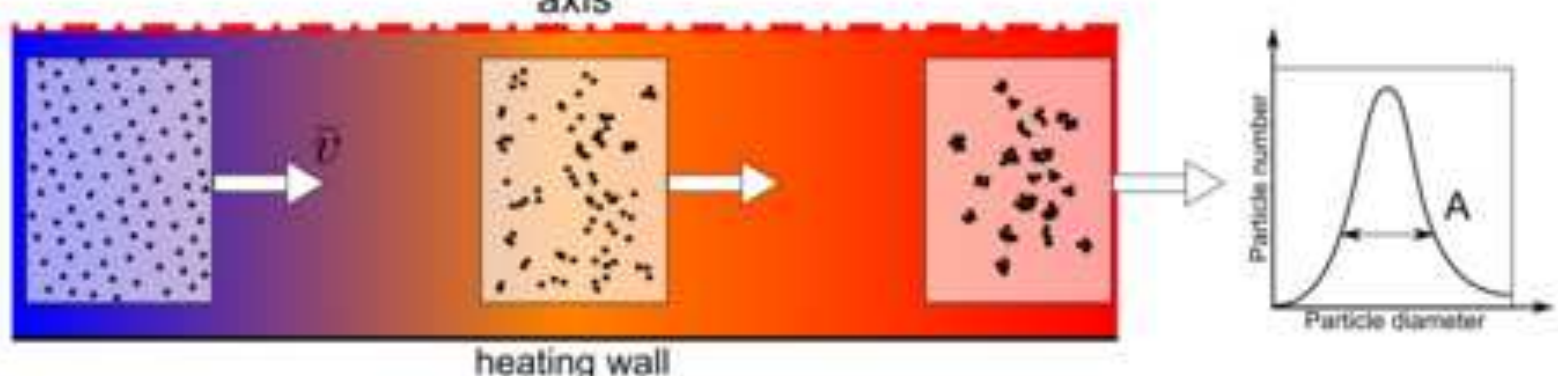

b)

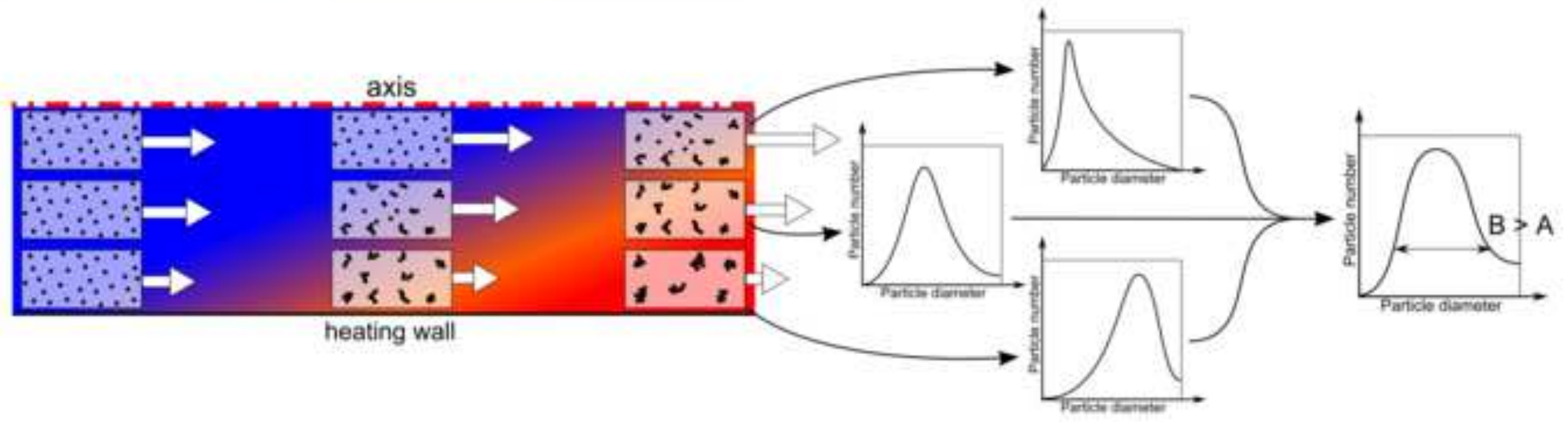

axis

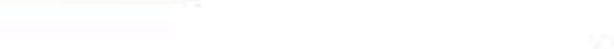

b 


\section{Figure2

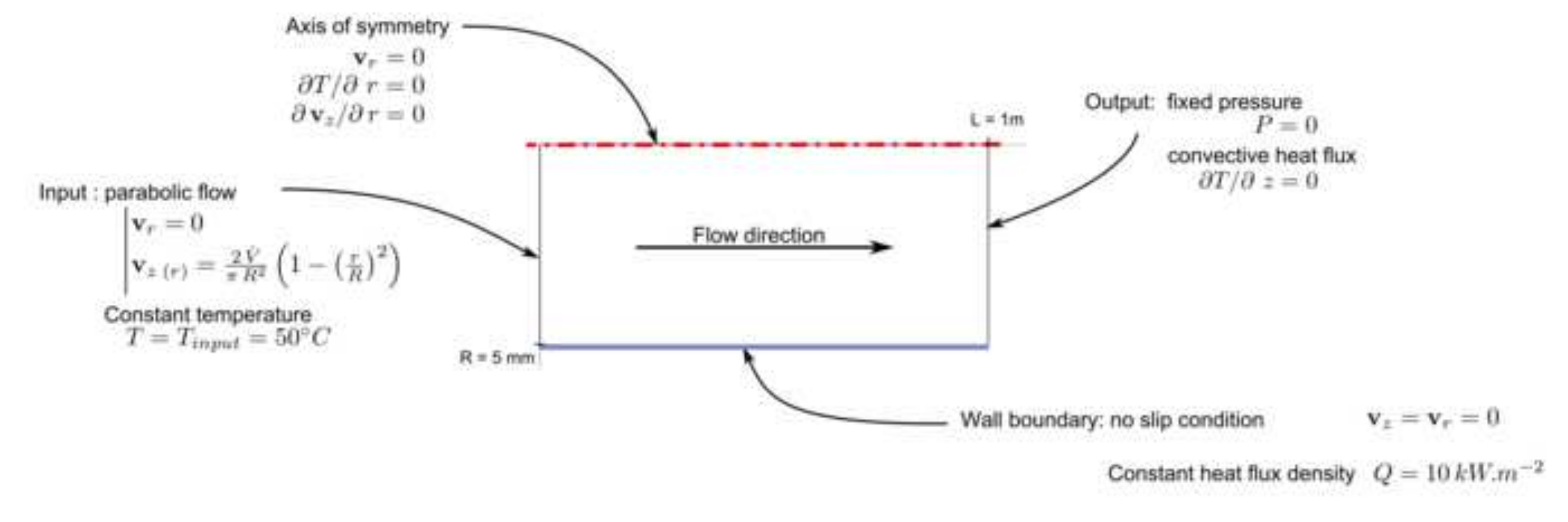

Axis of symmetr

$\mathbf{v}_{2} / \partial \mathrm{r}=0$

parabolic flow

$\mathbf{v}_{r}=0$

Constant temperature

$T=T_{\text {inpat }}=50^{\circ} \mathrm{C}$

$R=5 \mathrm{~mm}$

$v_{2}=\mathbf{v}_{r}=0$

.

ACCEPTED MANUSCRIPT 


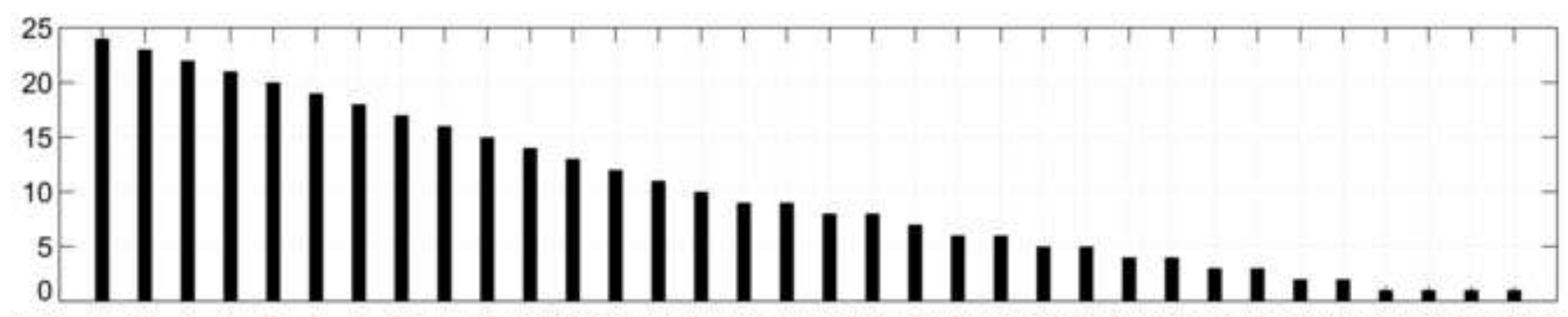

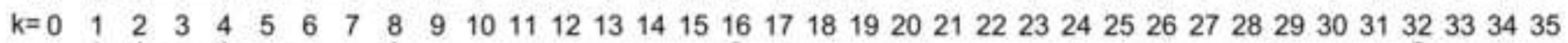

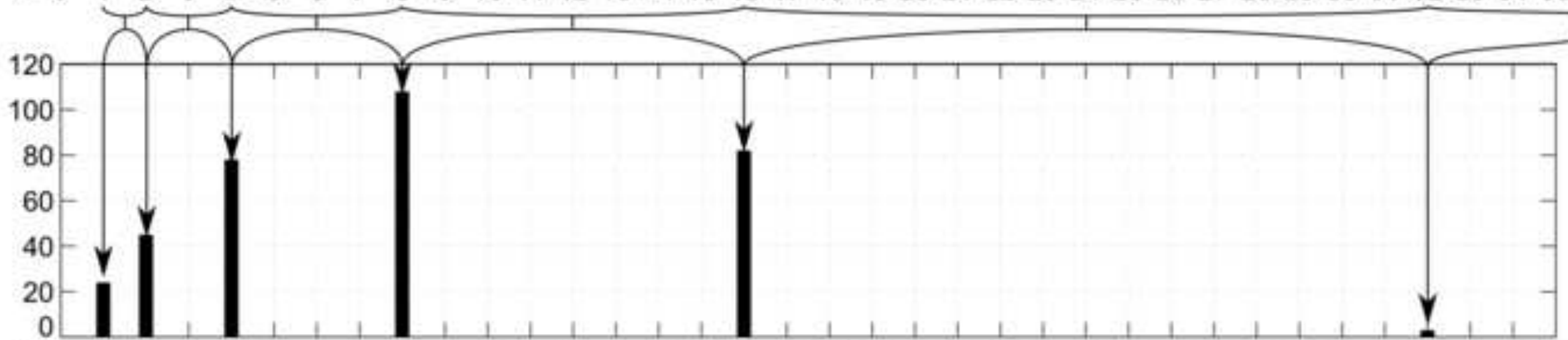

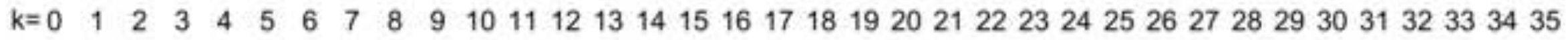
$i=0 \quad 1 \quad 2 \quad 3$ 4 5 

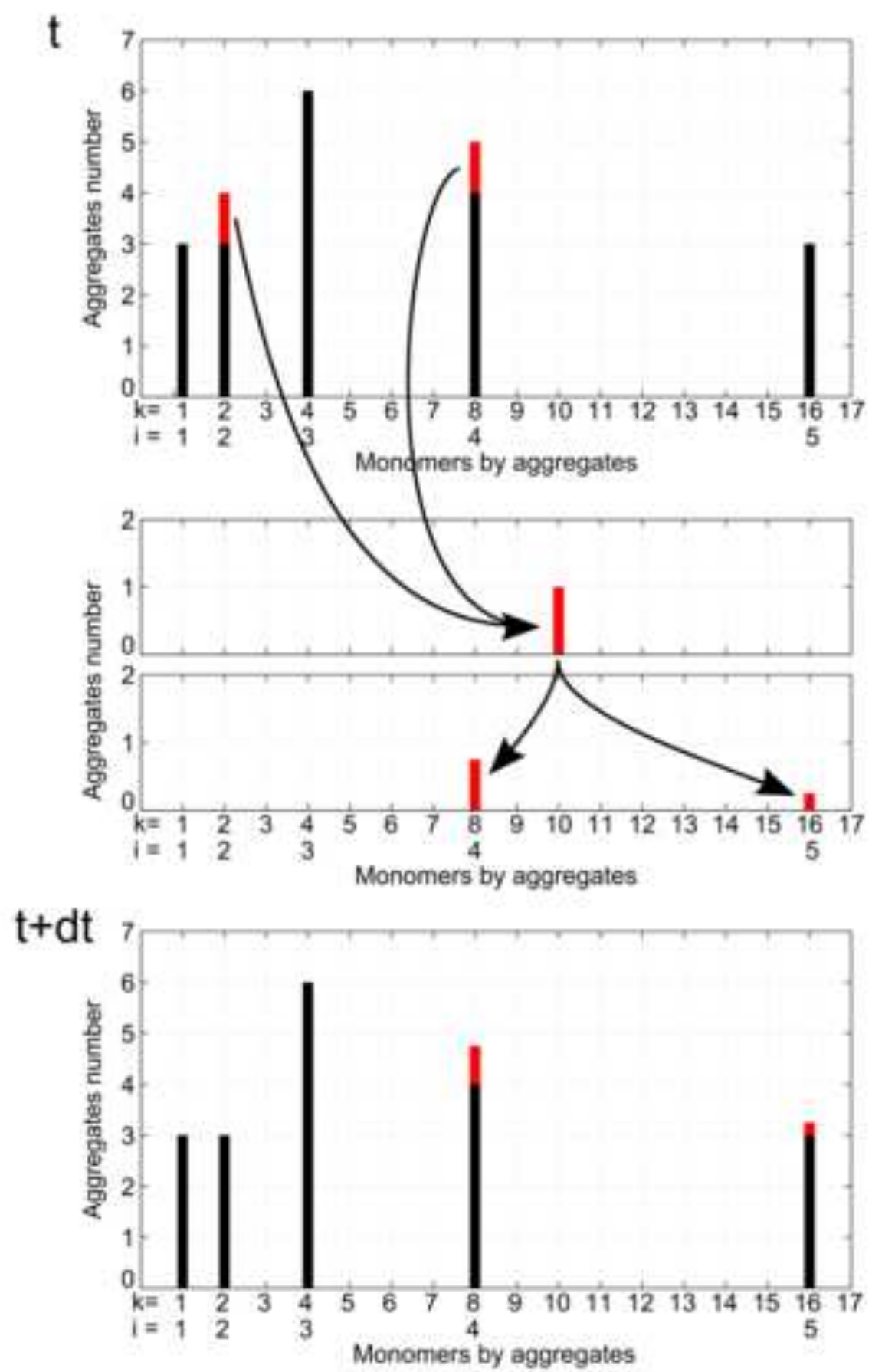


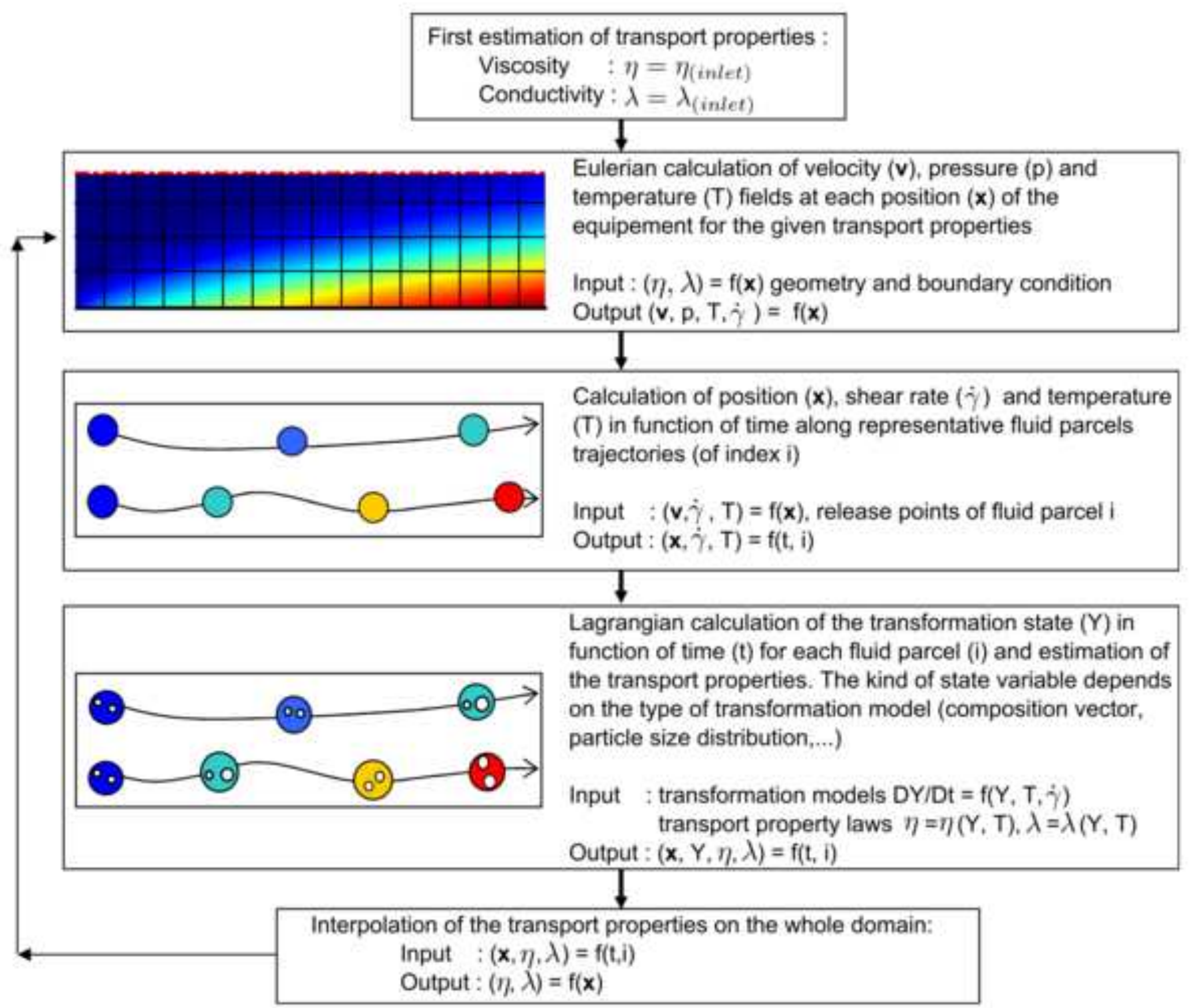

First estimation of transport properties :

Viscosity $: \eta=\eta_{(\text {inlet })}$

\section{$+$}

Eulerian calculation of velocity $(v)$, pressure $(p)$ and temperature (T) fields at each position $(\mathbf{x})$ of the

equipement for the given transport properties

Input: $(\eta, \lambda)=f(\mathbf{x})$ geometry and boundary condition Output $(v, p, T, \dot{\gamma})=f(x)$

Calculation of position $(\mathbf{x})$, shear rate $(\dot{\gamma})$ and temperatur $(T)$ in function of time along representative fluid parcels trajectories (of index i)

Input $\quad:(\mathbf{v}, \dot{\gamma}, \mathbf{T})=\mathrm{f}(\mathbf{x})$, release points of fluid parcel Output : $(\mathbf{x}, \dot{\gamma}, T)=f(t, i)$

Lagrangian calculation of the transformation state $(Y)$ in function of time ( $t$ ) for each fluid parcel (i) and estimation of the transport properties. The kind of state variable depends on the type of transformation model (composition vector, transport property laws $\eta=\eta(\mathrm{Y}, \mathrm{T}), \lambda=\lambda(\mathrm{Y}, \mathrm{T})$

Output : $(\mathbf{x}, \mathrm{Y}, \eta, \lambda)=f(t, i)$ 

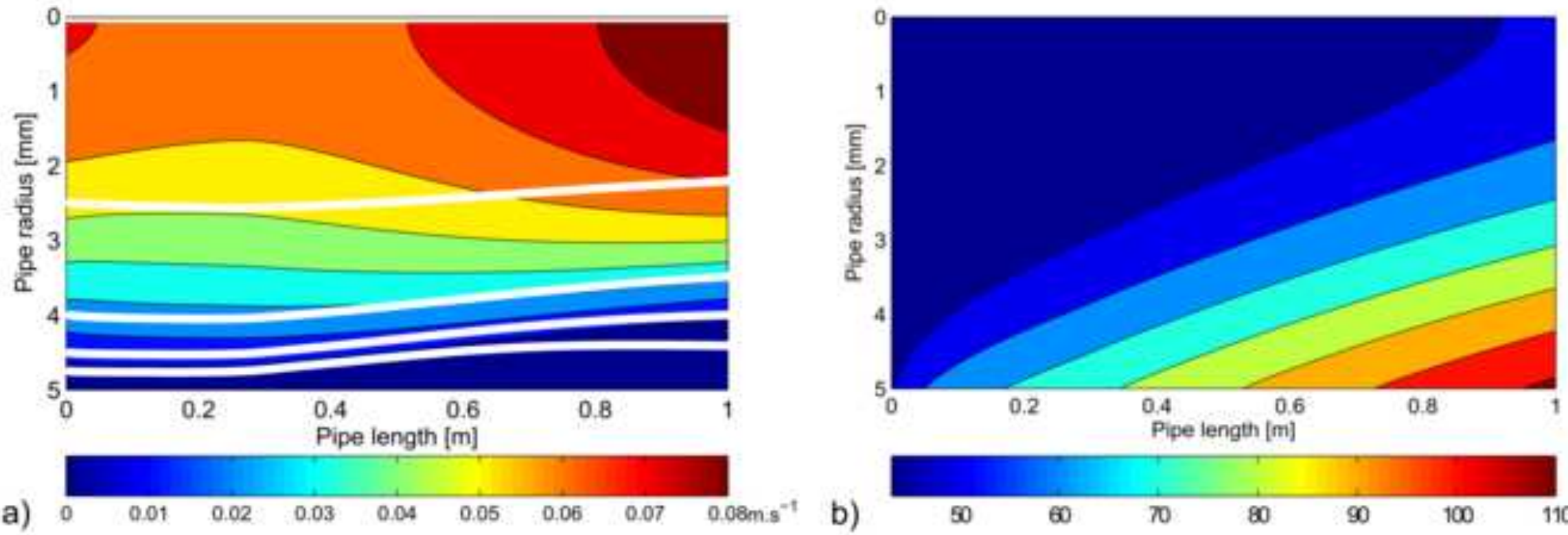

a)

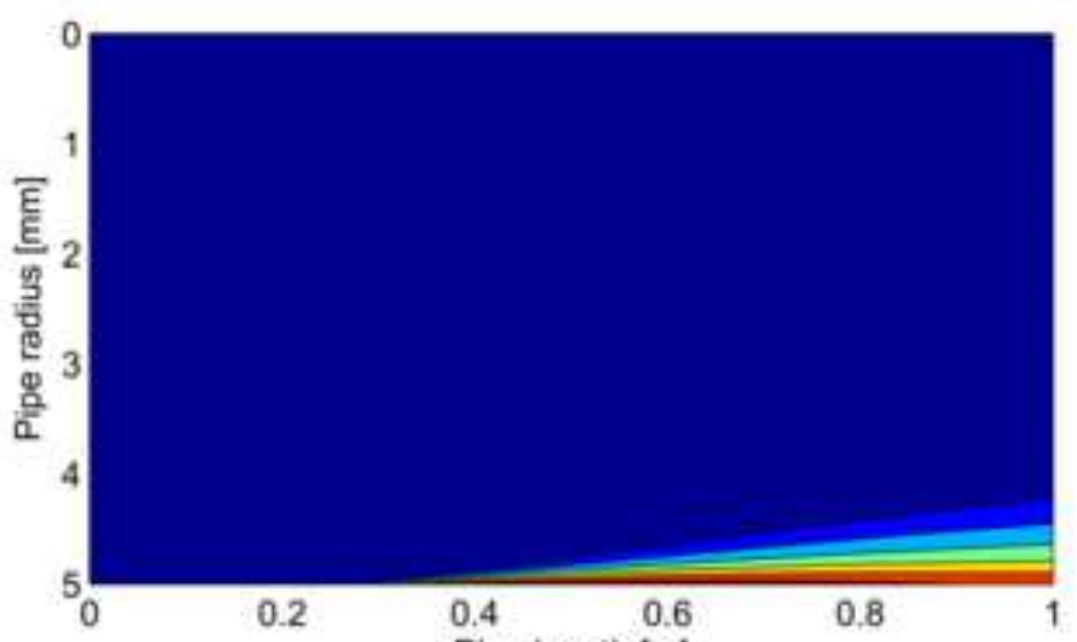

c)

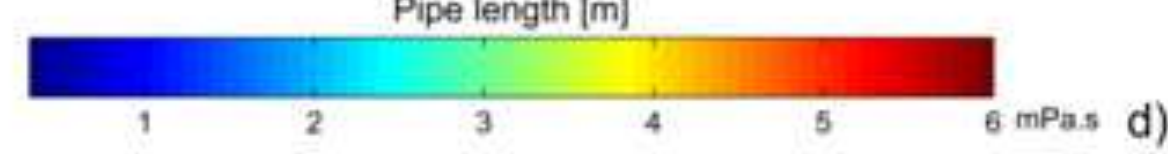

b)
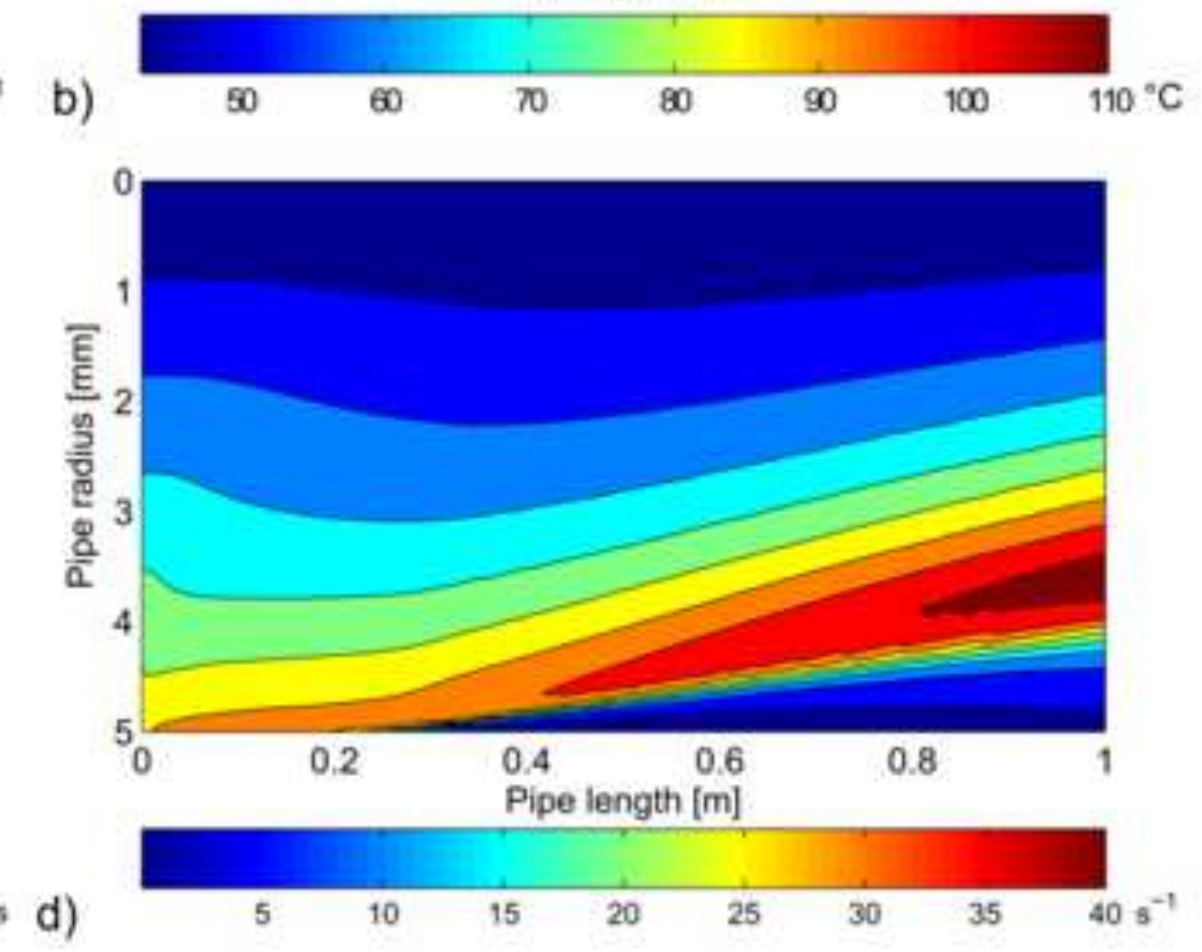

d)

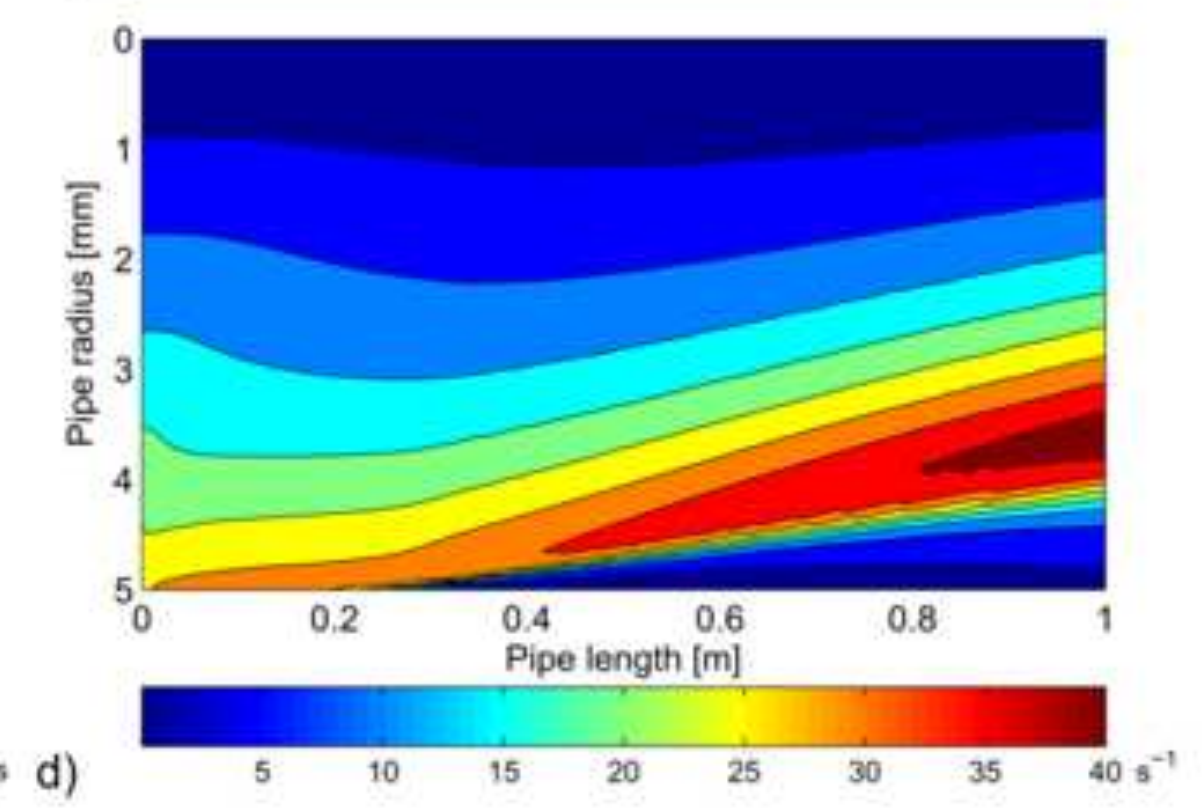




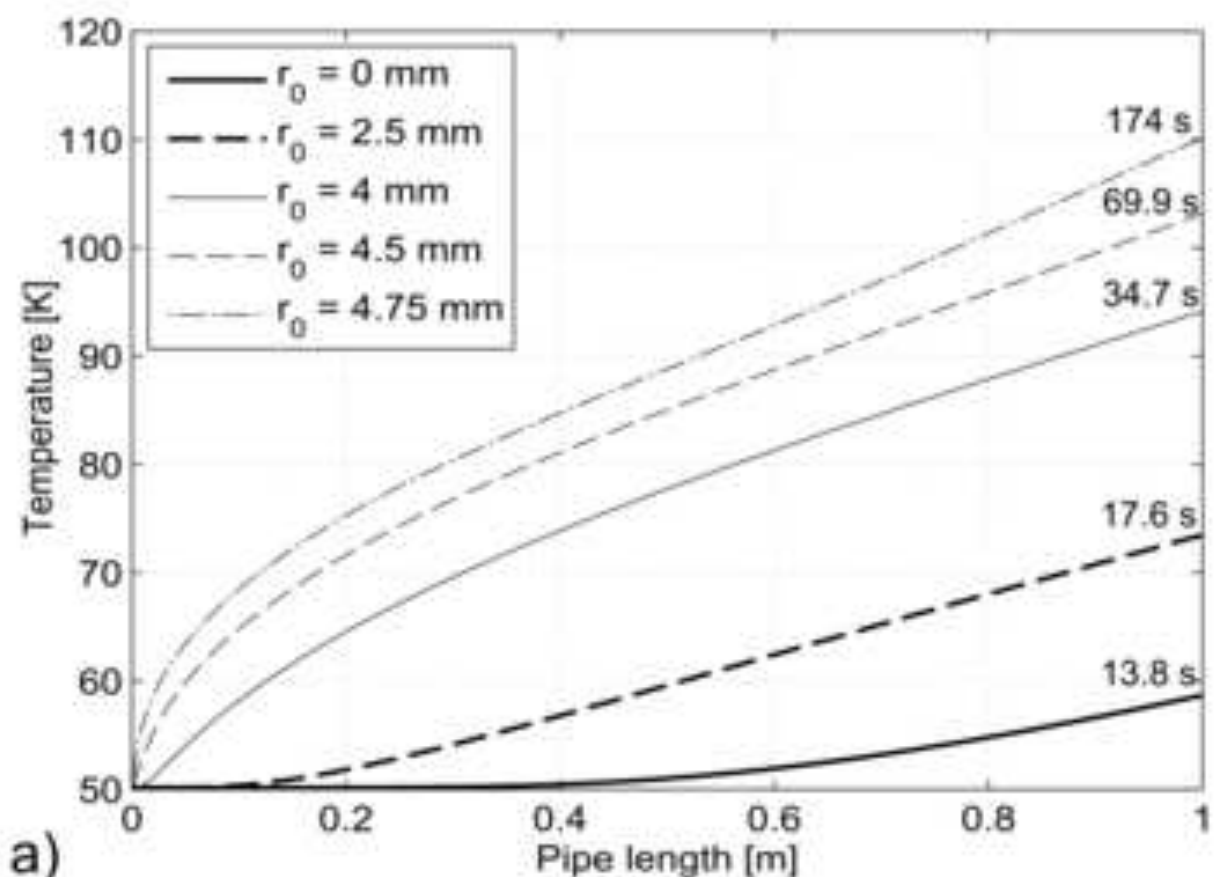

a)

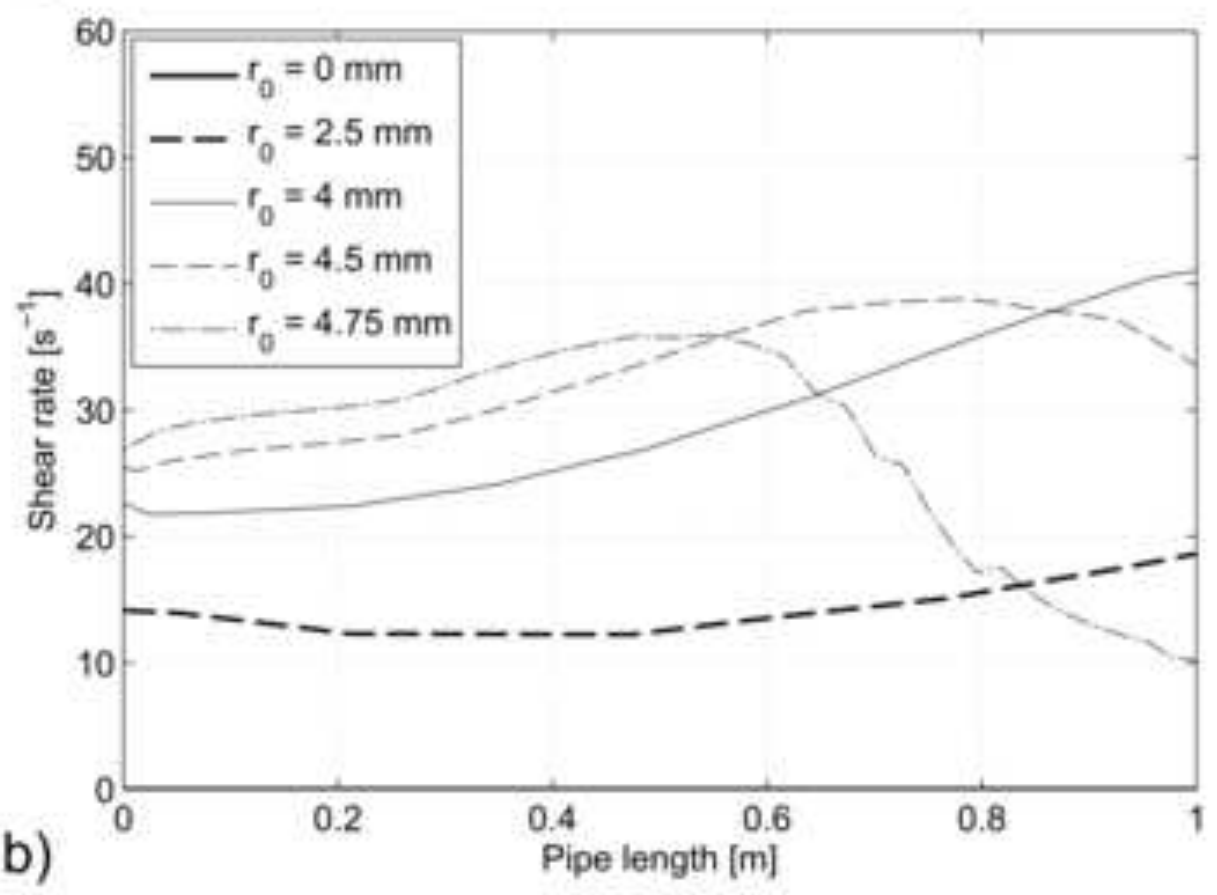



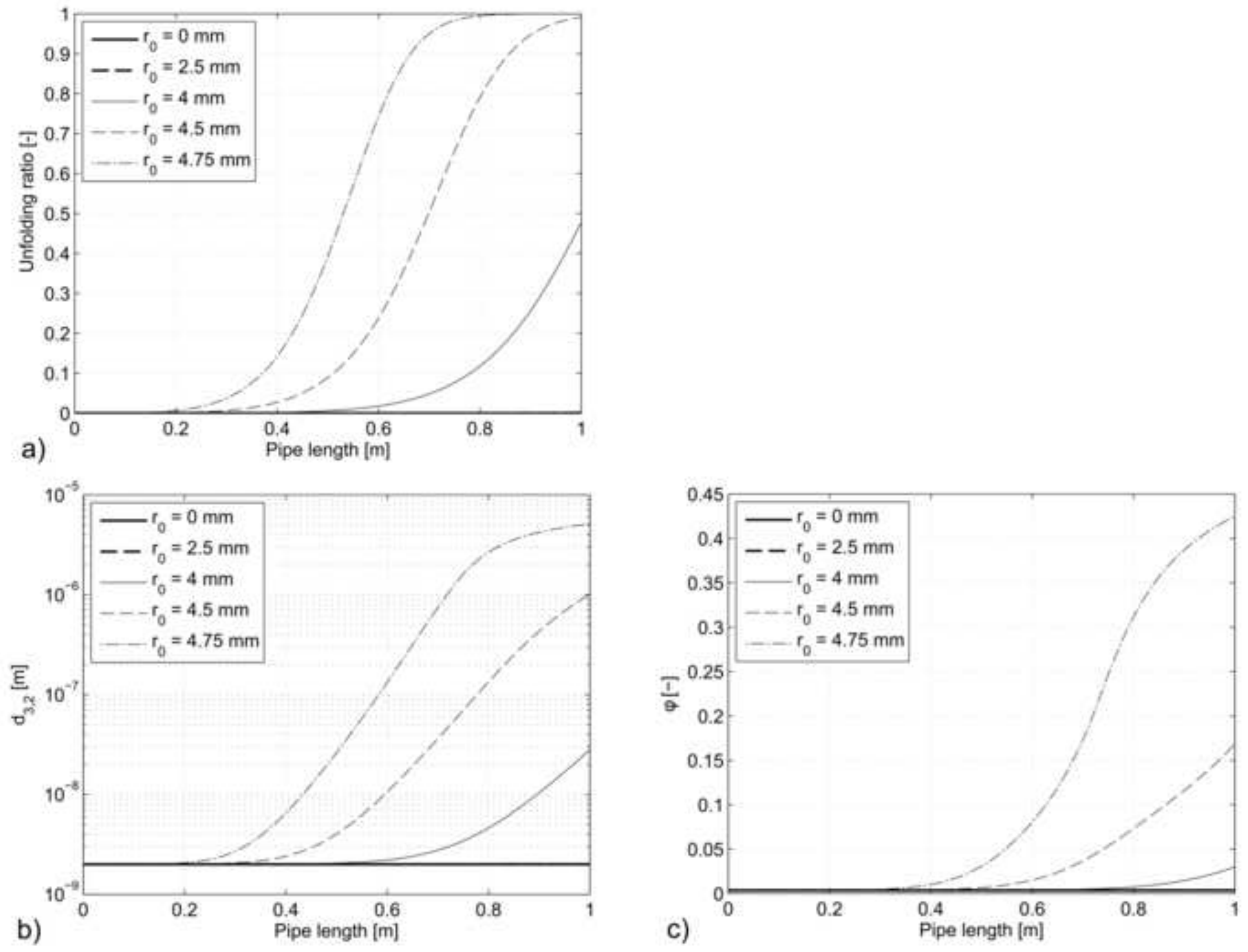


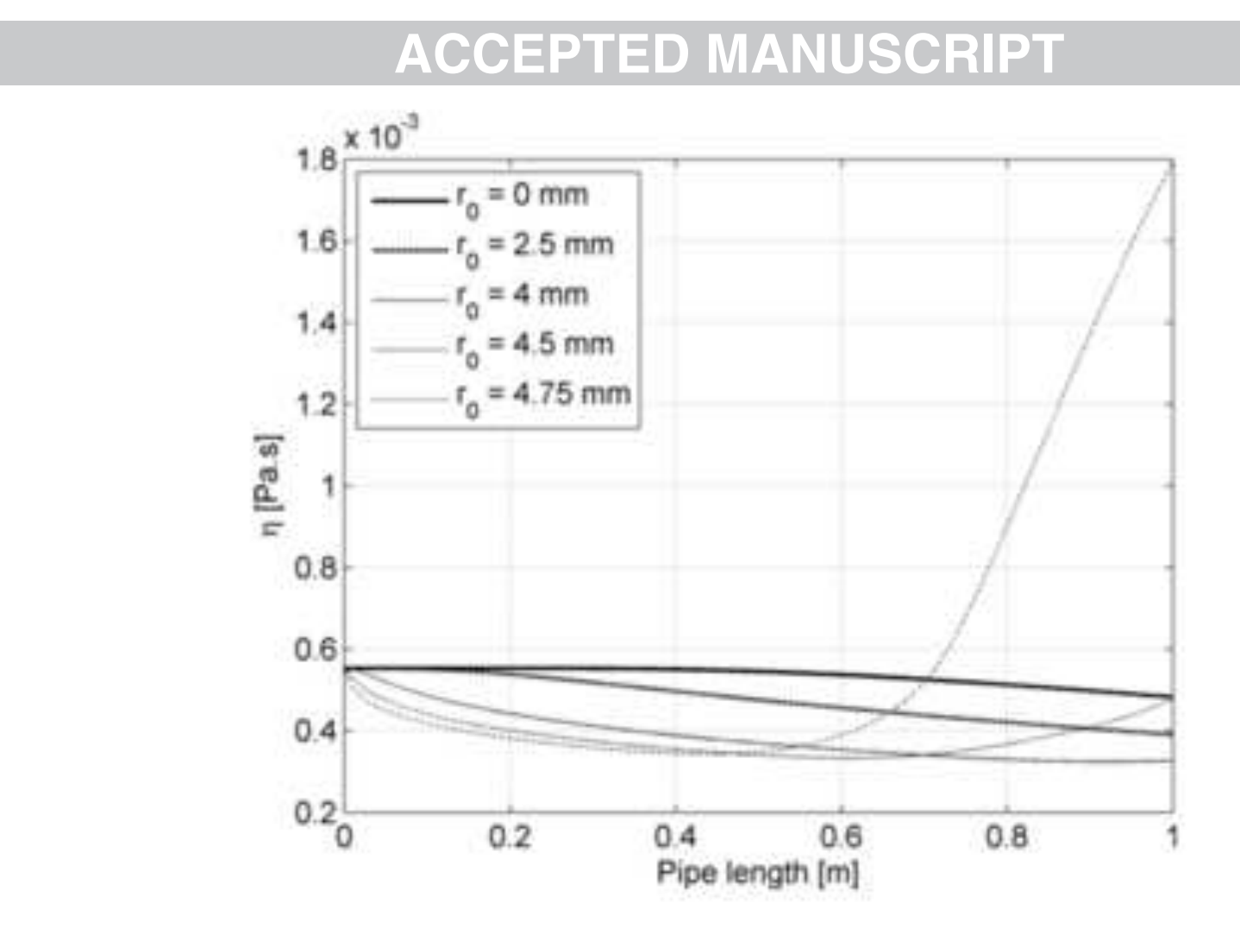

Figures

ipe length [m]

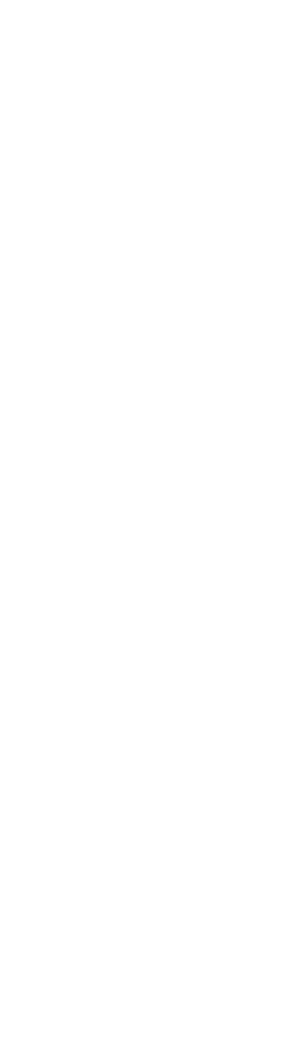

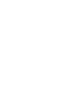
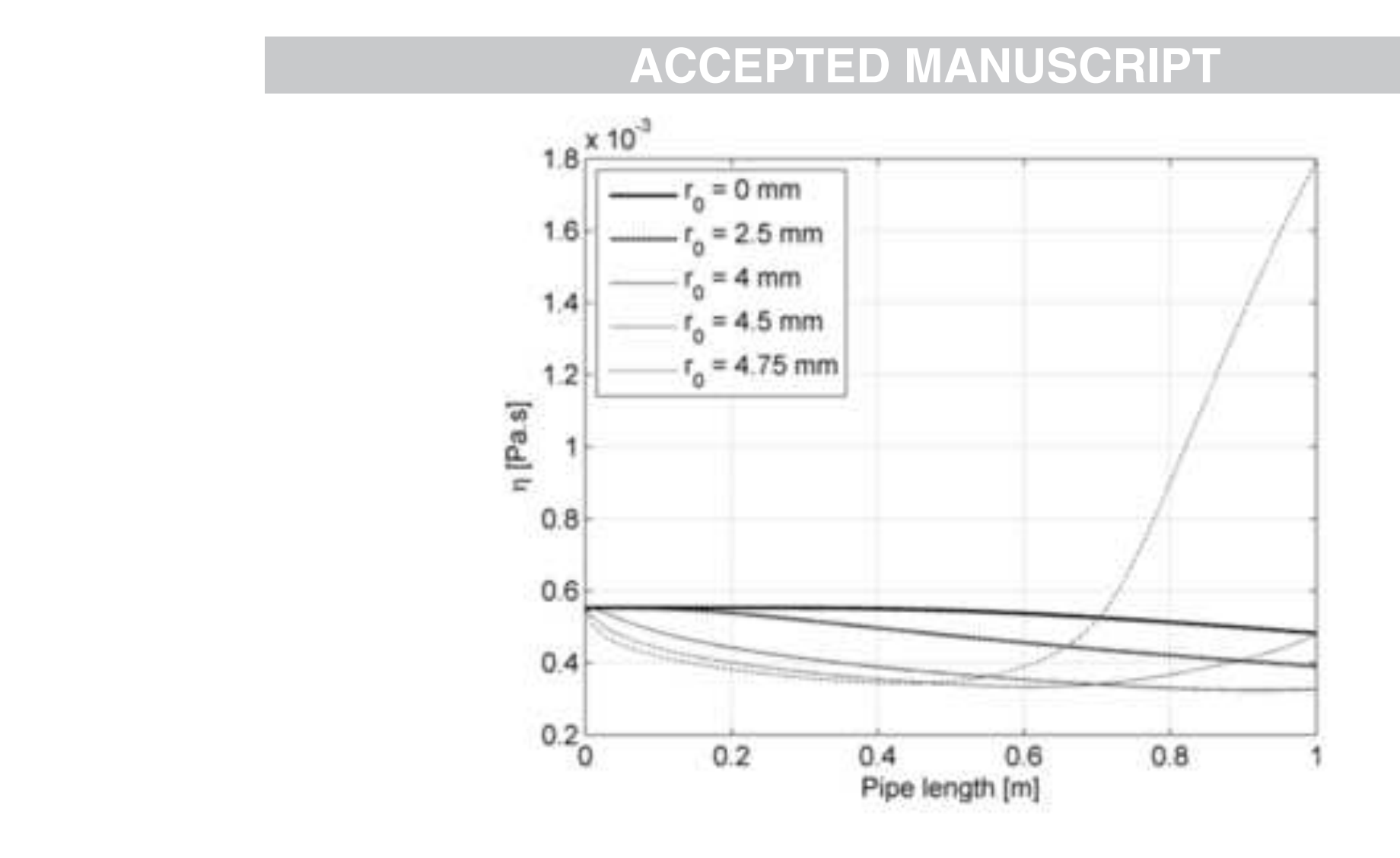

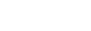

(a)

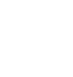

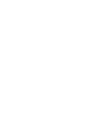

(n)
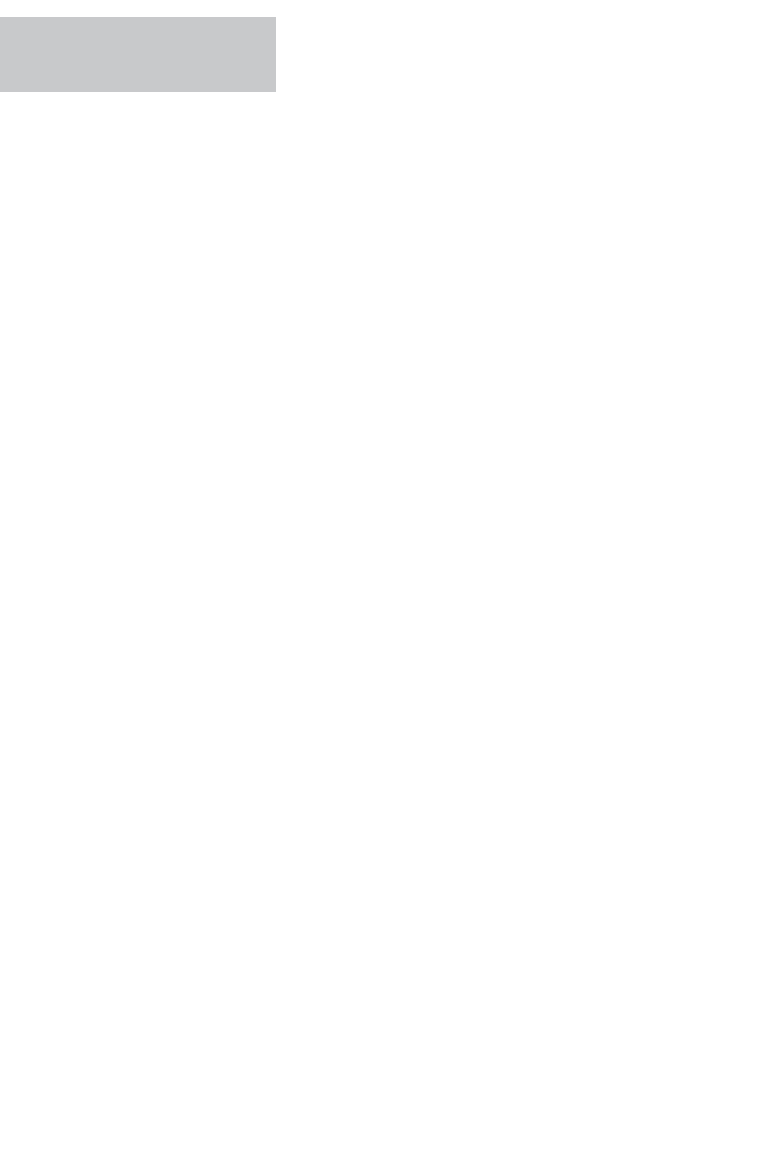

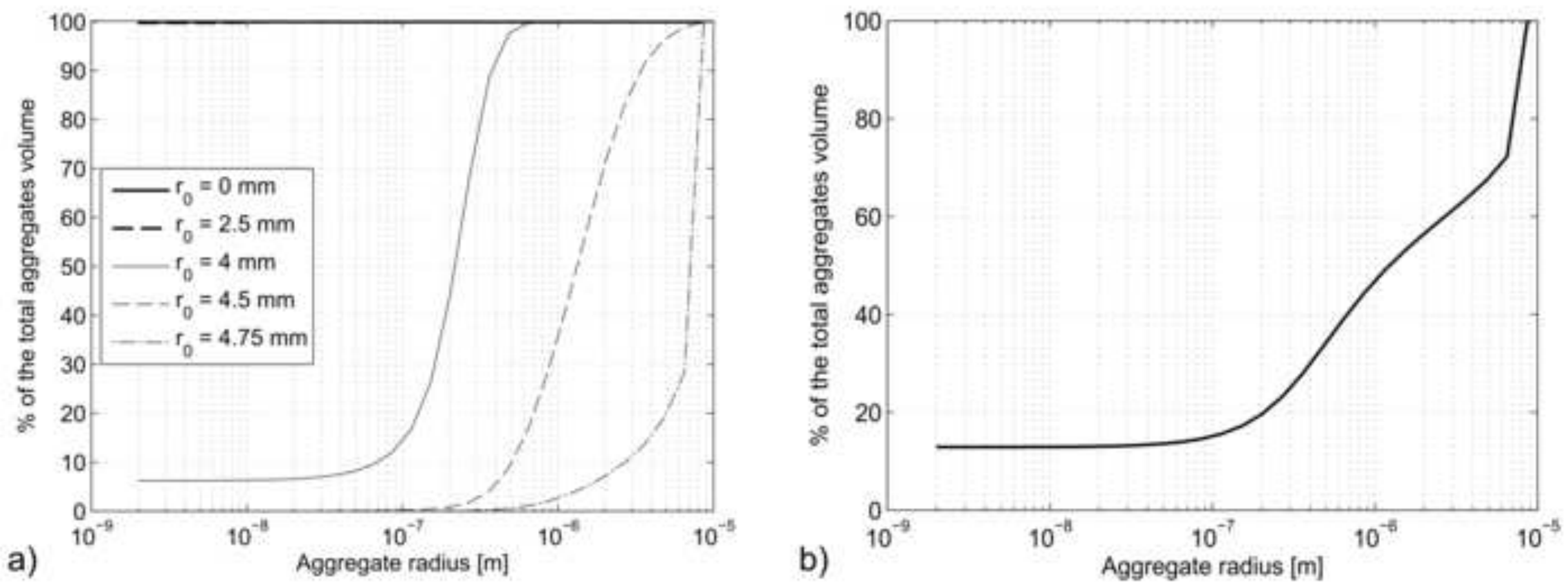

a)

Aggregate radius [m] b)

Aggregate radius [m]
$10^{-5}$ 
- We study $\beta$-lactoglobulin aggregation during continuous thermal treatment.

- Aggregation is estimated along Lagrangian trajectories using sizes class method.

- Transformation is coupled with fluid flow and heat transfer classically estimated.

- Thermal and shear rate histories along the domain drive the aggregation magnitude.

- Obtained particle sizes distribution shows product diversity unlike 1D model. 


\author{
Elsevier Editorial System(tm) for Journal of Food Engineering \\ Manuscript Draft
}

Manuscript Number: JFOODENG-D-11-01030R4

Title: Coupling fluid flow, heat transfer and thermal denaturation-aggregation of beta-lactoglobulin using an Eulerian/Lagrangian approach

Article Type: Research Article

Keywords: beta-lactoglobulin; thermal treatment; particle aggregation; population balance equation; computational fluid dynamics; Euler-Lagrange method

Corresponding Author: Dr Artemio Plana-Fattori,

Corresponding Author's Institution: AgroParisTech

First Author: Etienne Chantoiseau

Order of Authors: Etienne Chantoiseau; Artemio Plana-Fattori; Christophe Doursat; Denis Flick

Abstract: The transformation of liquid food product under heat treatment is often represented by considering average temperature evolution along the exchanger and by assuming plug-flow. Our aim is to demonstrate that thermal denaturation-aggregation of whey proteins can be more realistically represented by taking into account the different dynamical and thermal histories associated with fluid parcels which progress more or less quickly, far or close to the heating wall, inside the processing unit. A numerical approach is proposed for evaluating the thermal denaturation-aggregation of whey proteins, combining computational fluid dynamics and the population balance equation. The approach is illustrated by the evolution of a suspension of beta-lactoglobulin. Fluid flow and heat transfer are solved through the finite element method in the Eulerian frame, while product transformation is evaluated along representative Lagrangian trajectories. Outlet bulk results show that the product reaches a higher level of transformation than in assuming plug-flow and radially-independent temperature. 